OPEN ACCESS

Edited by:

Elena Zenaro,

University of Verona, Italy

Reviewed by:

Botir T. Sagdullaev,

Cornell University, United States Gabriel Gutiérrez-Ospina,

National Autonomous University

of Mexico, Mexico

*Correspondence:

Yunhua Yue

Yuehua.Yue@tongji.edu.cn

Tian Tian

fcctiant@zzu.edu.cn

Specialty section:

This article was submitted to

Neurodegeneration,

a section of the journal

Frontiers in Neuroscience

Received: 21 October 2021 Accepted: 09 December 2021 Published: 04 February 2022

Citation:

Zhang $Y$, Zhang $X$, Yue $Y$ and Tian $T$ (2022) Retinal Degeneration: A Window to Understand the Origin and Progression of Parkinson's

Disease? Front. Neurosci. 15:799526. doi: 10.3389/fnins.2021.799526

\section{Retinal Degeneration: A Window to Understand the Origin and Progression of Parkinson's Disease?}

\author{
Yanyan Zhang ${ }^{1,2}$, Xiaoguang Zhang ${ }^{2}$, Yunhua Yue ${ }^{2 *}$ and Tian Tian ${ }^{1 *}$ \\ 1 Department of Neurology, The First Affiliated Hospital of Zhengzhou University, Zhengzhou University, Zhengzhou, China, \\ ${ }^{2}$ Department of Neurology, Yangpu Hospital, School of Medicine, Tongji University, Shanghai, China
}

Parkinson's disease (PD), the second most prevalent neurodegenerative disorder, manifests with motor and non-motor symptoms associated with two main pathological hallmarks, including the deterioration of dopaminergic cells and aggregation of alphasynuclein. Yet, PD is a neurodegenerative process whose origin is uncertain and progression difficult to monitor and predict. Currently, a possibility is that PD may be secondary to long lasting peripheral affectations. In this regard, it has been shown that retinal degeneration is present in PD patients. Although it is unknown if retinal degeneration precedes PD motor symptoms, the possibility exists since degeneration of peripheral organs (e.g., olfaction, gut) have already been proven to antedate PD motor symptoms. In this paper, we explore this possibility by introducing the anatomical and functional relationship of retina and brain and providing an overview of the physiopathological changes of retinal structure and visual function in PD. On the basis of the current status of visual deficits in individuals with PD, we discuss the modalities and pathological mechanism of visual function or morphological changes in the retina and focus on the correlation between visual impairment and some representative structural features with clinical significance. To consider retinal degeneration as a contributor to PD origin and progress is important because PD evolution may be monitored and predicted by retinal studies through state-of-the-art techniques of the retina. It is significant to integrally understand the role of retinal morphological and functional changes in the neurodegenerative process for the diagnosis and therapeutic strategies of PD.

Keywords: Parkinson's disease, visual deficits, morphological changes, neuropathology, retinal imaging technology

\section{INTRODUCTION}

Parkinson's disease (PD) is a chronic and multisystemic neurodegenerative disease characterized by a series of motor symptoms (bradykinesia, resting tremor, rigidity, and postural instability) and non-motor neurologic phenomena (sleep disturbances, autonomic dysfunction, gastrointestinal, urogenital problems, cognitive decline, psychiatric symptoms, sleep abnormalities, as well as visual disturbances) (Santos Garcia et al., 2019; Xu et al., 2019). Age is a main factor of PD, and the global impact of the disease is emerging, with its prevalence at around $>2 \%$ of all persons above 65 years of age, and $>4 \%$ of all persons over the age of 80 years (Gbd 2015 Neurological Disorders Collaborator Group, 2017; Santos Garcia et al., 2019; Xu et al., 2019). Individuals suffering from PD 
are increasing and are estimated to be 12 million patients by 2050 (Ggbd 2016 Parkinson's Disease Collaborators, 2018), and early diagnosis and intervention of PD pathology plays a very important role in medical health.

Elucidating the derivation of pathological changes is critical for the early diagnosis and intervention of PD. However, the pathological origin of PD is debated. Consistent with the dopamine depletion and pathologic a-Syn in the nigrostriatal pathway described in previous studies, the two pathologic hallmarks have observed in peripheral nervous system and various end-organs that lead to numerous non-motor manifestation of PD including autonomic impairment (Postuma et al., 2015), sleep dysregulation, mood disorder (Ortuno-Lizaran et al., 2018b) dementia, and visual alterations (Ortuno-Lizaran et al., 2018a). Increasing studies have now discussed a possibility of PD pathology initially arising outside of the central nervous system (CNS). Indeed, the spreading of a-Syn to the brain via peripheral inoculation (e.g., olfaction, gut) has been amply elucidated (Kim et al., 2019). Visual symptoms, including glaucoma (Pavlenko et al., 2018), dry eyes (Friedman, 2004; Tamer et al., 2005; Reddy et al., 2013), visual hallucinations (Onofrj et al., 2006; Williams et al., 2008), and deficits in color vision appears early in the disease in PD patients (Stenc Bradvica et al., 2015). As shown in Table 1, PD patients suffer from different eye disorders [Blinking (London et al., 2013; Seiple et al., 2016), eye movement dysfunctions (Anderson and MacAskill, 2013; Hanuska et al., 2015; MacAskill and Anderson, 2016), pupillary imbalance (Jain et al., 2011), nuclear cataract (Lai et al., 2015; Klettner et al., 2016)]. Ophthalmological examinations of subjects with PD also suggest a loss of color vision problems, visual acuity impairment as well as the deficiency of spatial contrast sensitivity (Uc et al., 2005; Bertrand et al., 2012; Weil et al., 2016; Guo et al., 2018). The cellular and molecular studies have demonstrated loss of dopaminergic amacrine cells and retinal ganglion cells are partially responsible for the reduced contrast sensitivity, impairment in visual acuity, or electroretinographic response in individuals with $\mathrm{PD}$ (Yenice et al., 2008; Esteve-Rudd et al., 2011; Koens et al., 2018; Ortuno-Lizaran et al., 2020). On post-mortem observation of PD patients, authors have found the loss of dopaminergic retinal cell and the aggregation of a-Syn (Diederich et al., 2014; OrtunoLizaran et al., 2018a). Interestingly, it has recently been proposed that animal models with retinal damage due to intravitreal injection of minimal doses of neurotoxins display symptoms of experimental PD (Willis et al., 2014). A further example is that the retinal exposure of welding flash is associated with increased incidence of PD (Willis, 2005). Conversely, an immune tolerance induced by eyes via administration of antigens into the anterior chamber could be used as a therapeutic approach to promote neuroprotection for neurodegenerative diseases (Farooq and Ashour, 2013; Toscano-Tejeida et al., 2016; Pineda-Rodriguez et al., 2017). Thus, it is reasonable to conclude that the retina may be intimately involved with the onset and progression of $\mathrm{PD}$ as a potential precipitating factor outside of the CNS.

The retina presents a unique opportunity to study the CNS. First, it shares a common origin, structure, and physiology with the brain in terms of nervous and microvascular systems
(Cameron et al., 2017). Over the past decades, investigators have attempted to access the tools that leverage the accessibility of the retina to better understand and diagnose $\mathrm{PD}$. The retinal degeneration, retinal ganglion cells (RGCs) loss, and retinal thinning as well as visual disorders were observed in $\mathrm{PD}$ and animal models. As the only portion of CNS, furthermore, the retina is capable of reliable and precise measures of highresolution imaging, retinal neurons, and vascular morphology therefore begin to be analyzed by ocular measurements from large studies utilizing tools. For instance, using the optical coherence tomography (OCT) imaging, some authors have found retinal nerve fiber layer (RNFL) thinning (Garcia-Martin et al., 2014b; Mailankody et al., 2015; Satue et al., 2017), and lower capillary perfusion density (CPD) and capillary afflux index in the retinal vascular morphology revealed by OCT angiography (OCTA) and fundus imaging (Guan et al., 2013; Robbins et al., 2021).

In this review, we systematically assess evidence in the field of PD with a focus on the morphological changes and visual dysfunction in the retina. We first review the anatomical and functional relationship of the retina and the brain. Also, the introduction and development of new and highly sensitive ocular technology were described. Special care is taken to discuss up-to evidences on retinal morphological alterations and visual disorders in PD patients, with the highlight of the correlation between several representative structural features and visual impairment in PD patients. Finally, we emphasized the role of some retinal morphological changes in diagnostic and prognostic progression for visual neuropathology of the neurodegenerative disease.

\section{STRUCTURE AND FUNCTION OF THE RETINA}

In embryological origin, the retina is derived from the neuroectoderm. The retina shares a common origin and similar anatomy with brain tissue. Revisiting some of the basic anatomy of the retina is helpful for appreciating the impact of diseases on the retina.

Retina and optic nerve are essential parts of the neural conduction systems, which consist of different cell types and play a crucial role in visual imaging. As an innermost, lightsensitive layer of sensory tissue in most vertebrates and some mollusks, the retina possesses complex and multilayer structures and many cells with microcircuits features and different functions (Figure 1). Morphologically, five classes of neuronal cells play the important role in shaping the structure of the retina, encoding visual information and regulating vision function. These component cells include photoreceptors (rods and cones), horizontal cells (HCs), bipolar cells (BCs), amacrine cells (ACs), and RGCs. In the normal condition, the light energy is converted to membrane potential changes in rod (RC) and cone (CC) photoreceptors in the outer retina layer (ORL). Within the outer plexiform layer (OPL), the photoreceptors convey light information to BCs under the modulation of HCs. Then, as a sole output neurons of the retina, RGCs within the inner 
TABLE 1 | Visual dysfunctions and manifestation in PD patients.

\begin{tabular}{|c|c|c|c|c|}
\hline Organ & Mechanisms & Main manifestations & Morbidity & References \\
\hline \multirow[t]{4}{*}{ (1)Eyelid } & Frontal DAN dysfunction & $\begin{array}{l}\text { (1) Blinking: } \\
\text { Bradykinesia of voluntary blinking, } \\
\text { Abnormalities of reflex blinking, } \\
\text { Reduced amplitude and blink rate }\end{array}$ & & $\begin{array}{l}\text { Postuma et al., 2015; Gbd } 2015 \text { Neurological Disorders Collaborator Group, 2017; Ggbd } 2016 \\
\text { Parkinson's Disease Collaborators, 2018; Santos Garcia et al., 2019; Xu et al., } 2019\end{array}$ \\
\hline & & (2) Apraxia of eyelid opening & & Ortuno-Lizaran et al., 2018b \\
\hline & & (3) Uncomfortable sensations, red eyes & $53-60 \%$ & Ortuno-Lizaran et al., 2018a \\
\hline & & $\begin{array}{l}\text { (4) Muscle disorder: } \\
\text { eyelid retraction, } \\
\text { eyelid ptosis, } \\
\text { lepharospasm }\end{array}$ & & Reddy et al., 2013; Kim et al., 2019 \\
\hline \multirow[t]{2}{*}{ (2)Eyebulb } & Extrapyramidal damage & $\begin{array}{l}\text { (1) Eye movement dysfunctions: } \\
\text { convergence insufficiency } \\
\text { Abnormal saccades } \\
\text { Smooth pursuit impairment }\end{array}$ & & Friedman, 2004; Tamer et al., 2005; Onofrj et al., 2006 \\
\hline & & (2) Diplopia & $10-30 \%$ & Williams et al., 2008 \\
\hline (3Pupil & Autonomic disorders & $\begin{array}{l}\text { Pupillary imbalance: } \\
\text { Reduced amplitude of contraction, } \\
\text { Prolonged contraction time }\end{array}$ & & Guo et al., 2018 \\
\hline (3)Lens & Mitochondrial dysfunction & Nuclear cataract & $16-24 \%$ & Uc et al., 2005; Weil et al., 2016 \\
\hline \multirow[t]{3}{*}{ (4) Retina } & Retinopathy & (1) Visual acuity & $70 \%$ & Bertrand et al., 2012; Ortuno-Lizaran et al., 2020 \\
\hline & DAN dysfunction & (2) Spatial contrast sensitivity & & Esteve-Rudd et al., 2011 \\
\hline & a-Syn deposition & (3) Color vision & & Esteve-Rudd et al., 2011; Willis et al., 2014 \\
\hline (5) Optic nerve & Macular thickness & Visual field defects & $60-70 \%$ & Willis, 2005 \\
\hline \multirow[t]{3}{*}{ (6) Visual cortex } & Cortex impairment & (1) Visuospatial deficits & $30-60 \%$ & Toscano-Tejeida et al., 2016; Pineda-Rodriguez et al., 2017 \\
\hline & & (2) Visual hallucination & & \\
\hline & & (3) Facial expression recognition & & \\
\hline \multirow{3}{*}{$\begin{array}{l}\text { (7) Other auxiliary } \\
\text { apparatus }\end{array}$} & Retina DAN dysfunction & (1) Glaucoma & $30-40 \%$ & Uc et al., 2005; Farooq and Ashour, 2013 \\
\hline & & (2) Dry eyes & $50 \%$ & Cameron et al., 2017; Satue et al., 2017; Ortuno-Lizaran et al., 2018b \\
\hline & & (3) Rapid eye movement sleep behavior & & Garcia-Martin et al., 2014b \\
\hline
\end{tabular}




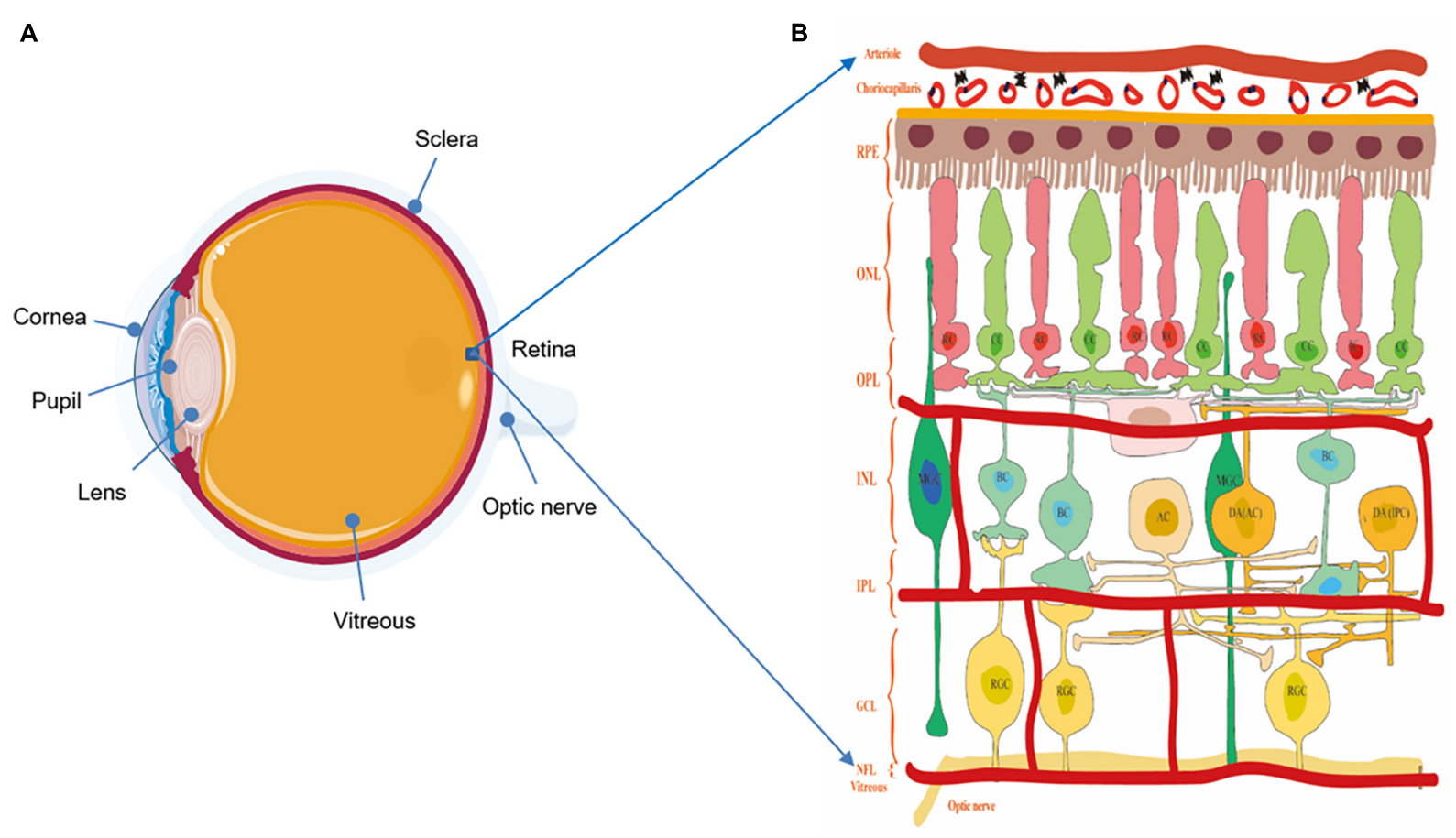

FIGURE 1 | (A) The structure of the eyeball. (B) The structure of the retina and diagram of the retinal neurons. Notably, understanding the physiologic structure and function is critical for better exploring the relationship of visual function and morphological changes. The retina possesses complex and multilayer structures and a large number of cells with microcircuits features and different functions. ILM, inner limiting membrane; RNFL, retina nerve fibers layer; GCL, ganglion cell layer; IPL, inner plexiform layer; INL, inner nuclear layer; OPL, outer plexiform layer; ONL, outer nuclear layer; ORL, outer retina layer; RPE, retinal pigmented epithelium; RC, rod cell; CC, cone cell; BC, bipolar cell; HC, horizontal cell; AC, amacrine cell; DA AC dopaminergic amacrine cell; DA IPC, dopaminergic interplexiform cell; RGC, retinal ganglion cell.

plexiform layer (IPL) contact BC and ACs at the inner nuclear layer (INL), projecting their axons to higher visual centers (Archibald et al., 2009; Schmidt et al., 2011). Aside from the above vertical and horizontal cell bodies, there are cells or related neurotransmitters mediating visual information, including the retinal pigment epithelium (RPE) with the capacity of visual pigment regeneration, and Müller glial cells (MGC) involved in neuronal metabolism, synaptic pruning, and neurotrophy (Vecino et al., 2016). These cells mediate retinal signaling in vertical and horizontal directions, and these are vital in shaping color vision, spatial resolution, and vision sensitivity (Weil et al., 2016).

\section{Dopaminergic Neurons in the Retina}

Malmfors (1963) first described the role of catecholamines in rat retinal function and regulation, involving in the light/dark adaptation and reshaping retinal circuitries. Subsequently, dopaminergic neurons have been identified in human retina, and overlap with neighboring DA cells as well as other retinal cells (the cone-rod, horizontal cells, and ganglion cells) (Frederick et al., 1982). In vertebrate retina, DA neurons contact two other types of amacrine cell (AII and A17) and interplexiform neurons (IPC) (Figure 1). The amacrine cells, via gap junctions, receive input from BCs and pass visual information to RGCs and the same cell types, modulating visual processing of the flow of photoreceptors-driven visual information. Compared with the AII amacrine cells, in scotopic conditions, the A17 amacrine cell receives GABAergic inputs instead of excitatory glutamatergic inputs from rod bipolar cells, and it plays a role in converging rod signals and amplifying the effects of low light stimulation (Hillman et al., 1995). DA cells are stimulated to release functional dopamine as an essential neuromodulator in photopic conditions, making synaptic contacts between DA cells and affecting on gap junction permeability both at the level of photoreceptors interactions with HCs and at the level of DA cells communication (Cameron et al., 2009; Zhang et al., 2014). In return, DA cells alter the action potential firing rate of their own cells and regulate DA release when receive excitatory or inhibitory feedback information.

In addition to this excitatory and inhibitory feedback system, the modulation of retinal DA cells conditions and dopamine concentration has diurnal variation, with low levels at night and higher levels during the day. From functional perspectives, some DA cells are light-evoked, involving in regulating the light/dark adaptation and electrophysiological communication between retinal cells in different layers depending on the circadian rhythm (Cohen et al., 1992). Also, some dopaminergic cells can activate spontaneously and alter DA level in the darkness. In turn, the DA effects on photoreceptor cells, BCs, ACs, and HCs (Popova, 
2014), reshaping photomechanical movements and survival, to enhance flicker response of retinal rod pathway (Hampson et al., 1992), and regulate visual stimuli of cells communication as well as protects RNFL (Yavas et al., 2007). Knowledge of these anatomical connections and visual progressing demonstrated that DA is a chemical neurotransmitter in the retina, promoting synaptic effects and visual information to regulate electrical activity and retinomotor movements.

\section{Ganglion Cells and Retinal Nerve Fiber Layer}

In retinal physiology, RGCs, the output neurons that project visual information from the inner retina to the brain, extend to the lateral geniculate nucleus (LGN) via a nerve fiber tract complete with an oligodendrocytic myelin sheath (Henderson et al., 2008). There are numerous subtypes of retinal cells, such as photoreceptors, HCs, BCs, and ACs, making synaptic contact with RGCs in the inner plexiform layer through different communication systems, including acetylcholine, dopamine, glutamate, glycine, and gaba-aminobutyric acid. Influenced by light, RGCs receive photosensitive information through either direct or indirect circuitry, and act as the final common pathway in the flow of visual information to the optic nerve and brain cortex (Figure 1). Sparkly, the melanopsin-containing retinal ganglion cells (mRGCs), accounting for about $0.3-0.8 \%$ of the total ganglion cells within the retina, represent a specialized class of RGCs that respond to light without rod and cone information input (Hattar et al., 2002). Some authors therefore think that mRGCs constitute a third class of photoreceptors and are directly photosensitive. In addition, mRGCs are also responsible for the non-image forming pathways, mediating the circadian rhythm and pupil constriction that are involved in mood and sleep behaviors (Güler et al., 2008). Previous studies demonstrated that GCL thinning is relevant to lower visual acuity, contrast sensitivity loss, and color deficiencies.

The RNFL is the inner most layer of the retina and is composed largely of axons of RGCs. Many studies investigated the ganglion cells' death is inevitably reflected on thinning RNFL thickness, relatively presenting the number of RGCs axons loss (Henderson et al., 2008). Recently, the OCT and OCTA have been used in the investigation of structural changes and measures of the vertical retinal layers in the retina in vivo. RNFL thinning demonstrated the dopaminergic neuronal loss and decreased axons of RGCs, effecting retinal neuronal processing and electrophysiological function (Bodis-Wollner et al., 2014a).

\section{Microvascular and Choroidal Structure in the Retina}

In addition to retina nervous systems, evidence has implicated retinal small vessel plays an important role in structural and functional changes in the retina. Based on the potential risk the role of cerebral small vessel disease for the development of PD plays (Guan et al., 2013), some studies demonstrated retinal microvascular changes have been studied retinal capillary plexus vessel density (VD) and perfusion density (PFD) as well as structural changes in PD (London et al., 2013; Robbins et al.,
2021). Thus, structural changes in retinal microvascular are seen as non-invasive biomarkers for the disease detection.

Considering the common embryologic and anatomic characteristics of retinal vascular with the cerebral circulation, microvascular changes in the retina may correlate with vascular changes in the CNS. The retinal vasculature is a window in vivo non-invasive assessment of microvasculature in the body (Figure 1). In embryology, the ophthalmic artery originates from the internal carotid artery gives off the central retinal artery, providing nutrients and oxygen to the inner layer of the retina. Metabolic waste and carbon dioxide from the retina are excreted into the sinus via the central retinal vein through the superior ocular vein. Central retinal arteries and veins form a terminal branch retinal circulation network on the surface of the retina. In addition, microvasculature of the retina shares similar neurobiology and electrophysiological function with those in CNS (Ge et al., 2021).

\section{MORPHOLOGICAL AND FUNCTIONAL TECHNOLOGIES IN THE RETINA}

As the eye is an extension of the brain, the retina displays similarities to the brain in anatomy, functionality, and pathological responses to environmental insult. So, to detect retinal morphological parameters of brain pathologies using imaging techniques seems reasonable.

Optical coherence tomography (OCT) is a non-invasive observational technique based on reflectance intensity of light, providing some real-time information of the retina on structure using infrared interferometric imaging (Figure 2). The OCT enables an optical biopsy of retina to provide two/threedimensional cross-sectional images of the target tissue using the interference of infrared radiation (Langwinska-Wosko et al., 2016). In 1991, the first OCT image was described by David Huang in the anterior chamber of an ex vivo bovine eye (Huang et al., 1991). Subsequently, Fercher et al. (1993) and Swanson et al. (1993) showed the first in vivo measurements of human retinal structure using the non-contact and high resolution technique in 1993. Retinal OCT imaging detects and quantifies the structural correlates of these visual symptoms of patients, provides histologic level information about retinal nerve fiber layer, cells, and retinal blood vessels. With the growth of OCT scientifically and economically, OCT assesses the three-dimensional outer retina thickness in the higher image pixel density and quality of OCT (Fujimoto and Swanson, 2016). For instance, spectral domain OCT (SD-OCT) uses a wavelength of $820 \mathrm{~nm}$, diminished the vitreous signal, and improved imaging of the macular choroid (Ha Usler and Lindner, 1998), reaching deeper structures of the retina. Sweptsource OCT (SS-OCT) reaches deeper penetration using a wavelength of $1,020 \mathrm{~nm}$. In addition, the special OCT, OCT angiography (OCTA) imaging, allows for blood flow visualization (Gulmez Sevim et al., 2019; Robbins et al., 2021). This is an emerging approach for imaging retinal vessels, can visualize microvasculature based on motion contrast from flowing blood to assess the blood pressure, intraocular pressure, vascular 
density of the superficial capillary plexus, deep capillary plexus, and choriocapillaris (Zhang et al., 2018). Therefore, retinal OCT imaging not only costs lower, but provides insight into the underlying pathophysiology in the earlier disease process, compared to conventional neuroimaging methods, such as the fundus color photograph, fundus fluorescein angiography, and B-ultrasonography. These new, cost-effective, high-resolution imaging tools enabled increases in imaging speeds and quantity, further catering clinical need of diagnosis and therapeutics of diseases, and increasing clinical data demonstrated the important role of OCT in diagnostic and therapeutic applications of many diseases. The OCT has become a new and highly sensitive method for detecting and analyzing some classic ocular pathologies in diseases.

Aside from the over-mentioned OsCTs, some techniques are applied to evaluating the functional performances of retinopathy of PD, including electroretinogram (ERG) and visual evoked potential (VP). The ERG reflects retinal comprehensive potential caused by a brief light stimulation recorded from the cornea. There are flash ERG and graphic ERG based on different forms of light stimulation (Netser et al., 2021). The flash ERG consists of a negative $A$ wave, a positive $B$ wave, and the OPs waves superimposed on the $B$ wave. Wave A mainly reflects the hyperpolarization activity of photoreceptors, while wave $B$ is generated by the electrical activity of MCs and BCs in the retina (Takatsuna et al., 1992; Meng et al., 2012; Normando et al., 2016). The wave OPs on the B wave are related to the electrical activity of ACs. The VEP is generated by the electrical activity in occipital cortex after the visual stimulation. The structural and functional changes in the retina cause the change of waveform amplitude and/or latency in VEP.

These techniques detect retinal nerve fiber layer (RNFL) thickness (Inzelberg et al., 2004; Hajee et al., 2009; Kirbas et al., 2013; Jimenez et al., 2014), central macular volumes, morphology in foveal vision (Pilat et al., 2016; Nunes et al., 2019), inner and outer retinal layers (Pilat et al., 2016), and retinal pigment epithelium (Uchida et al., 2018), and also assess retinal blood flow and vascular alterations as well as other pathological features of retina in PD patients. The monitoring retinal morphology and function are used for exploring hallmark signs corresponding to pathological conditions in different degrees and stages of PD.

\section{PATHOLOGICAL AND MORPHOLOGICAL CHANGES IN RETINA OF PARKINSON'S DISEASE}

The retina is a simple model of the brain in the sense that some pathological impairment and morphological changes from the retina may be observed or applicable to the degenerative diseases as valuable models. In the retina of PD patients, there were dopaminergic deficiency (Schmidt et al., 2011; Vecino et al., 2016), misfolded a-synuclein (Weil et al., 2016), retinal ganglion cells loss (Malmfors, 1963), thinning of retinal nerve fiber layer (Frederick et al., 1982; Hillman et al., 1995; Cameron et al., 2009; Zhang et al., 2014), or neuroinflammatory (Cohen et al.,
1992) at several levels of the visual pathway during pre-clinical stages. Moreover, studies on post-mortem of PD patients found the accumulation of misfolding $\alpha$-synuclein, the main culprit of the disease, in the retinal layers, especially the OPN of patients with early PD (Hampson et al., 1992; Yavas et al., 2007; Popova, 2014). Furthermore, evidence has indicated microvasculature changes as some potential biomarkers of retinal pathological changes in subjects with PD. Compared to the control cases using immunohistochemical staining and image analysis, Guan et al. (2013) observed the decreased capillaries branching as well as shortening length and enlarging diameter in capillary network in the substantia nigra, middle frontal cortex, and other brain stem nuclei. As van der Holst et al. (2015) described, increased risk of Parkinsonism was observed in population with cerebral small vessel disease. So these structural changes of the retina of PD have been shown the association with the progression, severity, and duration of the disease (Ma et al., 2018; Hasanov et al., 2019).

\section{A-Synuclein Deposits}

A-synuclein (a-Syn) is a neuropathological landmark, and its abnormal accumulation can induce neuronal death, disturbance in the dopamine mechanism, and synaptic effects (Henchcliffe and Beal, 2008). In normal physiological state, a-Syn is encoded by the SNCA gene, and belongs to the synuclein family that is involved with the exocytosis and synaptic function. In retina, a-Syn exists at the OPL, mediating membrane fusion synaptic vesicle and neurotransmitter release, fatty acid binding, cell signaling, and cell growth (Iwai et al., 1995; Burre et al., 2010; Breydo et al., 2012). In contrast, because of inducing risk factors in $\mathrm{PD}$, the a-Syn protein was transformed into truncation and multimerization from monomeric and tetrameric conformation, then converted to insoluble oligomers and amyloid fibrils, and eventually perturbed dynamic equilibrium of functional a-Syn (Kahle et al., 2001; Auluck et al., 2002; Liu et al., 2005). Moreover, aberrant aggregation of a-Synuclein has prion-like properties to trigger the intercellular transmission a-Syn fibrils (PFFs); it is time-dependent and changeable, implying that the propagation of a-Syn may be the key contributor to onset and progression of PD (Willis, 2008; Willis and Freelance, 2017; Figure 3).

Similarly, the conformational or metabolic changes of a-Syn polymer, such as phosphorylated a-Syn and abnormal accumulation into insoluble aggregates are cytotoxicity for cellular and molecular metabolism (Bodis-Wollner, 2009; Stenc Bradvica et al., 2015; MacAskill and Anderson, 2016) (Table 2). Some previous studies revealed the relation between retinal a-Syn aggregates and clinical and imaging manifestations of impaired vision in PD. Bodis-Wollner et al. (2014b) reported a-synuclein aggregations in the inner retina (GCL, IPL, and INL), and observed the loss of full retinal thickness in the retina of PD. These histopathological changes in retina provide a bridge between a-synuclein inclusions and RNFL thinning detected by OCT. In addition, based on the protein inclusions in GCL associated with the impaired GCs function, authors speculated a potential route of local transmission of the anormal protein between retina and central neurons systems. Similarly, Beach et al. (2014) has found that immunopositive phosphorylated a-Syn, a specific molecular marker of synucleinopathy, presence 

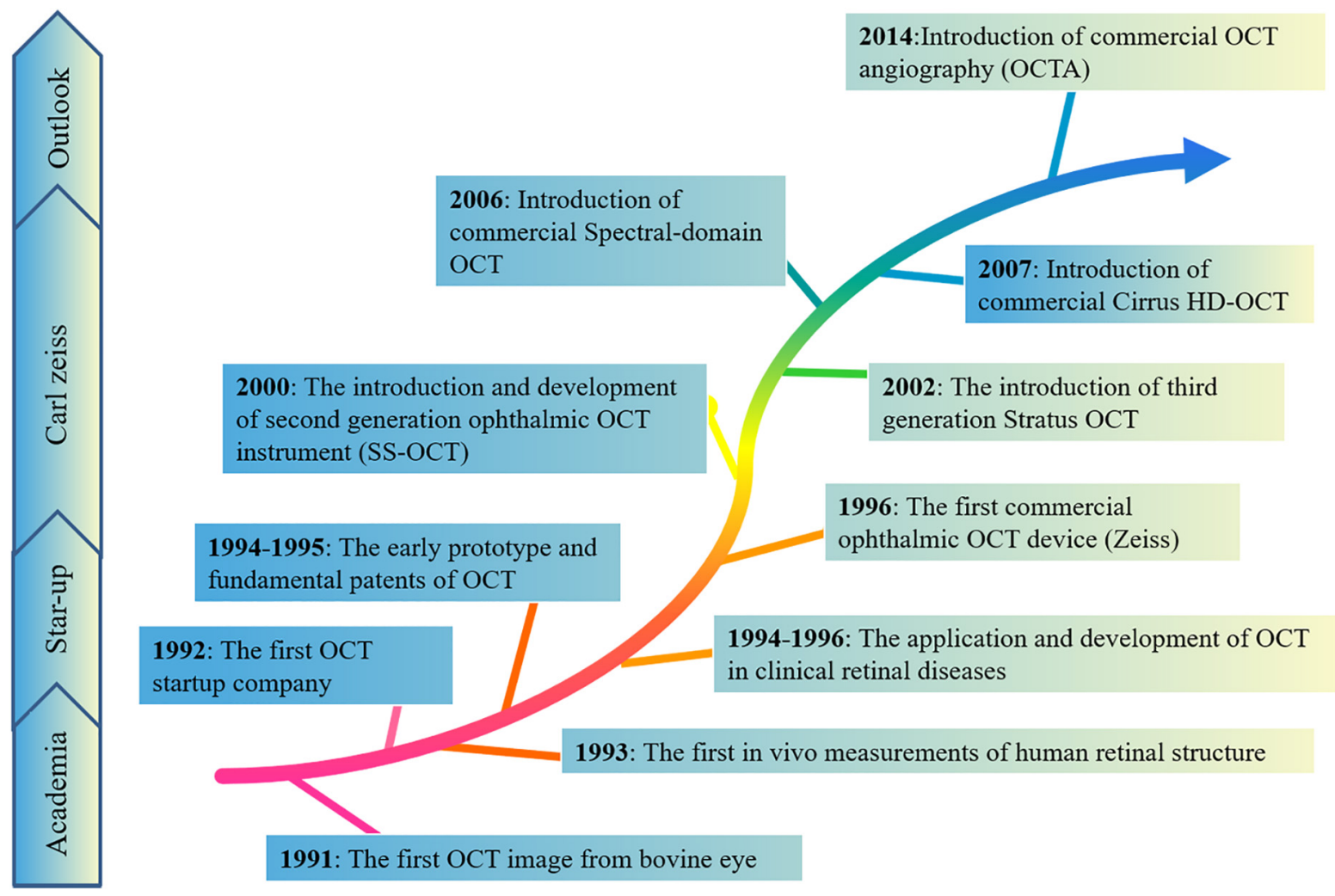

FIGURE 2 | The brief historical timeline marking events elucidating morphological and technologies in the retina. These new, cost-effective, high-resolution imaging tools enabled increases in imaging speeds and quantity, further catering to the clinical needs of diagnosis and therapeutics of diseases, and increasing clinical data demonstrated the important role of OCT in diagnostic and therapeutic applications of many diseases.

in the inner retinal surface of $\mathrm{PD}$ individuals paralleling to retinal thinning (GCL, IPL, and INL) has been reported with OCT (Altintas et al., 2008; Bodis-Wollner et al., 2014b). Further, Ortuno-Lizaran et al. (2018a) showed the p- $\alpha$-syn deposits in retinal ganglion cells or intrinsically photosensitive ganglion cells in patients with PD. As a-Syn may spread from neuron to neuron, the a-synuclein may rely on the long axons of the GCs to spread from the retina and brain (Bodis-Wollner et al., 2014b). However, there is not enough evidence to answer some pivotal questions including whether multifocal initiation of a-Syn pathology exists and how some a-Syn species transmit through neural connections or non-neuronal cells.

\section{Dopaminergic Deficiency}

Considering the demonstrated implication of dopaminergic cells in retina functions like those previously mentioned, an impairment in the retinal dopaminergic system is linked to visual symptoms in patients with PD. In 1988, Nguyen-Legros (1988) described the loss of dopaminergic neurons in the retina, and changes in the ERG, VEPs, and contrast sensitivity were observed. Compared the retinal dopamine content in patients who received levodopa therapy(treatment with the DA precursor levodopa $2-15 \mathrm{~h}$ before death)and who had not, Harnois and Di Paolo (1990) showed decreased DA in the retinas of subjects with PD. Furthermore, Ortuno-Lizaran et al. (2020) reported the dopaminergic cell degeneration and the loss of synaptic contacts, revealing a failure in DA cells through gap junctions that are involved in visual function. Interestingly, it has recently been proposed that the retina plays an important role in the regulation of the circadian system and motor function. Some articles have reported the motor impairment and circadian disorders in PD animal models (Willis et al., 2014). In turn, using levodopa in the retina (Willis, 2008) and timed light therapy (Videnovic et al., 2017) [a dopamine release stimulation ( $\mathrm{Li}$ and Tian, 2017)] showed an improvement of DA cells function, enhancing sleep, mood, and anxiety, and also improved motor function. Therefore, the retinal dopaminergic system is affected in PD and may explain the visual deficits, motor impairment, and circadian rhythm alterations described in patients.

With the development of ophthalmic techniques as mentioned above, updated retinal images in patients with $\mathrm{PD}$ exhibit reduced number of dopamine cells and dopamine concentration in the retina (Bodis-Wollner et al., 1987; Bodis-Wollner, 1990; Harnois and Di Paolo, 1990; Price et al., 1992). The measuring of the level of dopamine released by dopaminergic neurons is also beneficial for monitoring retinal morphological changes. Clinical data have demonstrated that dopamine and dopamine transporter (DAT) detected by single photon emission computerized tomography (SPECT) or positron emission tomography (PET) promise to be 


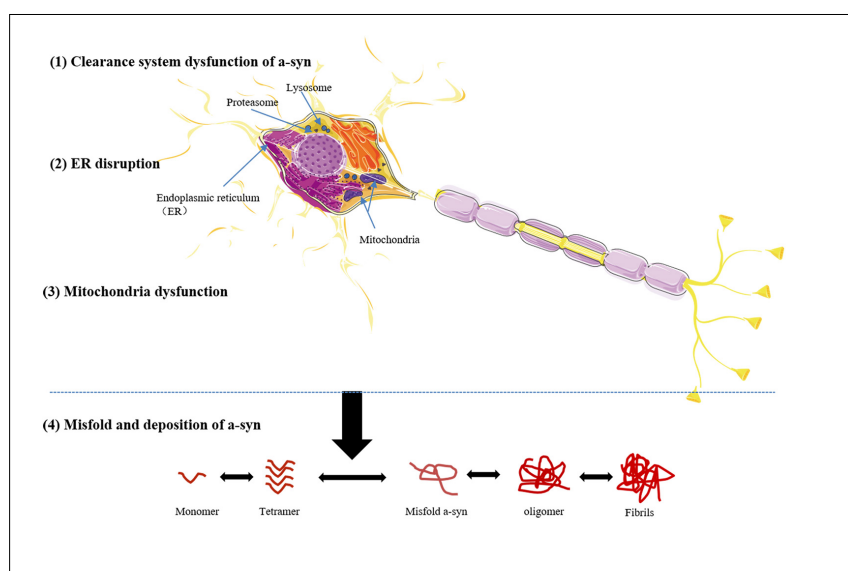

(5) Pathogenic $\alpha$-syn propagation in cells-to-cells

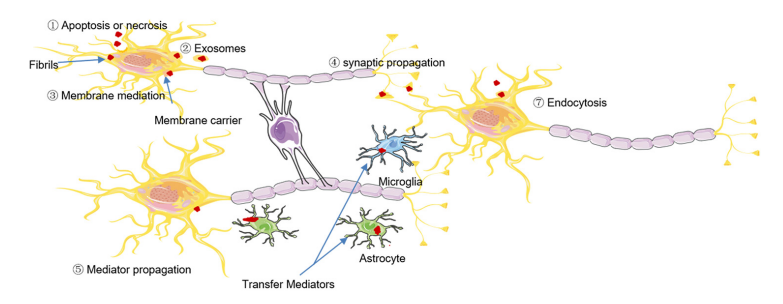

(6) The deposition of pathogenic $\alpha$-syn in Parkinson's disease

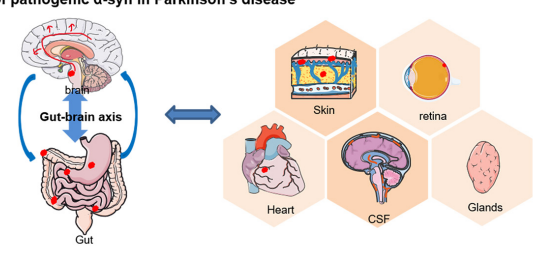

(7) The retinal degeneration in Parkinson's disease

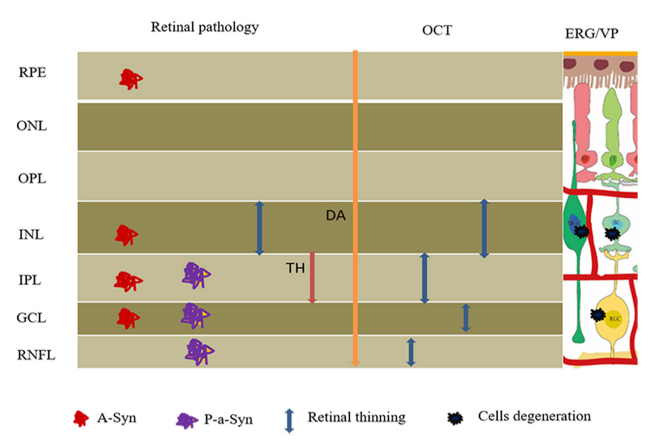

FIGURE 3 | Diagrammatic interpretation of the formation, propagation, and deposition of pathogenic a-synuclein. Certain risk factors effect on neurons, and initiate some pathological mechanisms associated with the etiology of PD, including (1) protein-clearance dysfunctions, (2) ER disruption, (3) mitochondria dysfunction. These pathological effects promote (4) abnormal a-Syn misfold and deposition. (5) Intercellular prion-like transmission of pathological a-Syn. Due to the propagative mechanisms of a-Syn similar to prions, abnormal proteins are released and transmitted via different mechanisms:Apoptosis or necrosis,exosomes, membrane mediation,synaptic propagation, mediator propagation, and so on. (6) The deposition of pathogenic $\alpha$-syn in Parkinson's disease. For the definitive derivation of a-Syn, the brain-first hypothesis and gut-first hypothesis appear to be better received in current research. Especially, pathological a-Syn also was found in retina, skin tissue, heart, CSF, and glandular secretions. These pathological changes are critical for interpreting and understanding of clinical symptoms of patients with PD. (7) The retinal degeneration in Parkinson's disease. objective and non-invasive markers to identify and determine retinopathy in PD patients (Nguyen-Legros, 1988; Wojtkowski et al., 2004; Biehlmaier et al., 2007). Also, abnormal transmitter production and atrophy in RGCs and RNFL caused lower dopaminergic cells to be identified using the OCT and be a promising marker to monitor the progression of the disease (Inzelberg et al., 2004). Thus, liked as pathological a-Syn, dopaminergic neurons loss may be the key factors triggering retinopathy in PD. Most experimental studies have shown that the formation and aggregation of a-Syn may induce a time dependent loss of DA neurons in the brain (Giordano et al., 2018). However, the specific pathophysiological mechanism of a-Syn in the retina and its relationship with the level of retinal dopamine remains to be further studied.

\section{Retinal Ganglion Cells Loss and Retinal Nerve Fiber Layer Thinning}

As previously mentioned, the ophthalmological examinations visualize on the surface of the retina, such as the RNFL and the retinal capillaries (attenuation, dilatation, aneurismal, and neovascular). Though it is not certain that all retinal thinning in $\mathrm{PD}$ is due to a-Syn aggregation or dopaminergic neuronal loss, the two main pathological hallmarks may damage retina structure (RGCs loss or RNFL thinning), interfere with signal transmission, and hence cause visual dysfunction.

Most non-invasive study of the retina in PD patients concentrated on the correlation of thinning RNFL detected by OCT. Inzelberg et al. (2004) first assessed with OCT and reported the RNFL thinning in patients with PD compared with controls. The results showed a decrease in the thickness of inferior quadrant RNFL near its entry to the optic nerve head (Inzelberg et al., 2004). Since then, it has been identified that the RNFL thickness was significantly thinner in four different quadrants, ranging superior, temporal (Altintas et al., 2008; Moschos et al., 2011), inferior (Inzelberg et al., 2004), and nasal (Shrier et al., 2012) in the retina of participants with PD. Likewise, the RNFL thickness in the macular region of PD was significantly lower than in the control groups (Moschos et al., 2011; La Morgia et al., 2013). Notably, the OCT quantification in macular seems to have a higher diagnostic yield than RNFL quadrants quantification (Polo et al., 2016). Sparkly, most studies revealed a significant thinning of the RNFL in the IRL (Hajee et al., 2009; Cubo et al., 2010; Albrecht et al., 2012) (constituting GCL, IPL, and INL) and in the central 5-mm quadrant of the macula (Albrecht et al., 2012; Garcia-Martin et al., 2014b), while no significant changes in the ORL of the retina (Hajee et al., 2009; Cubo et al., 2010; Adam et al., 2013).

The RNFL, as mentioned above, is formed from the axons of the ganglion cells and constitutes the output neurons of the retina. The thinness of the RNFL, specially GCL thinning, largely leads to decreased ERG responses (Cuenca et al., 2005). When comparing visual hallucination and OCT, Adam et al. (2013) reported that visual hallucinations positively correlate with retinal thinning in patients with $\mathrm{PD}$. On the contrary, an inverse correlation of IPL thickness with central contrast 
sensitivity was recently observed by Lee et al. (2014), and the correlation in PD is weaker that in control groups.

Moreover, there are studies in the literature reporting a correlation between the extent of the RNFL thinning and duration or severity of PD. For instance, Jiménez et al. (2014) demonstrated RNFL thickness correlation with disease severity, and reported a strong inverse correlation between RNFL thickness and the PD severity measured according to the Unified Parkinson's Disease Rating Scale (UPDRS) score. The result suggested the decreased RNFL thickness evaluated by OCT may be defined a simple biomarker for the clinical duration and average of PD. Similarly, Garcia-Martin et al. (2014a) demonstrated the more serious impairment of inner retinal layers in the patients with long disease duration, rather than healthy controls and PD with short disease duration.

\section{Retinal Microvascular and Choroidal Structural Changes}

Evidence has implicated the correlation of cerebral small vessel diseases with retinal microvascular changes detected by OCTA. In the Atherosclerosis Risk in Communities (ARIC) Study, Wong et al. (2001) detected that retinal microvascular abnormalities are associated with an increased incidence of stroke. Hughes et al. (2016) investigated associations between cerebral infarcts and white matter lesions and abnormalities of the retinal circulation, such as narrower arteriolar diameter, fewer arteriolar branching, and more tortuous venules. Further, clinical data demonstrated that these microvascular changes have been noted to have increased incidence of PD and retinal structural and functional alteration (Guan et al., 2013; van der Holst et al., 2015). Noninvasive tests of retinal vascular impairment are likely to serve as biomarkers for cerebral vascular changes in individuals with PD.

There are studies in the literature evaluating the retinal microvessel status in individuals with $\mathrm{PD}$. In a prospective study (Kwapong et al., 2018), scholars evaluated macula microvasculature and intraretinal layer thickness using SDOCT. The result demonstrated decreased microvascular density in retina and reported a strong correlation between RNFL thinning and the retinal microvascular abnormality. Also, Shi and collaborators (Shi et al., 2020) characterized lower retinal capillary density, decreased capillary perfusion density, and fractal dimension using OCTA, suggesting the role of retinal structural changes serving as a surrogate biomarker of cerebral changes in PD. On post-mortem analysis of brain tissue from patients with PD, Guan et al. (2013) also observed reduction in capillary branching, fragmentation of capillary, shortening vascular length, and larger diameter in the substantia nigra, middle frontal cortex, and brain stem nuclei. Recently, a cross-sectional study (Robbins et al., 2021) also compared relevant retinal parameters of individuals with $\mathrm{PD}$ and ageand sex-matched controls, found increased choroidal area, increased choroidal luminal area, and decreased capillary plexus vessel density and perfusion density in PD. Therefore, noninvasive retinal imaging, OCT, may detect structural changes in retinal microvascular as a novel technique for assessment and detection of PD.
However, the mechanism of retinal microvascular changes in $\mathrm{PD}$ is obscure. One may speculate that blood vessel regression effects retinal circulation network, disturbs energy metabolism and biochemistry functions. Retinal microvascular VD and PFD in individuals with PD, to some extent, may reflect the underlying blood vessel changes in neurodegenerative process of PD (Robbins et al., 2021). Further, comparing vascular regression and pathological features of PD in a-Syn overexpression mouse model, Elabi et al. (2021) observed dynamic changes in retinal microvascular morphology accompanied by a pathological accumulation of $\alpha$-syn deposit. The result suggests the role of retinal microvascular pathology as an important pathophysiological marker in PD (Elabi et al., 2021). Moreover, early discoveries that the eye consists of unique surface molecules and cytokines, and presents some immune responses similar to those in CNS (Streilein, 2003), so retina may display similarities of microvascular changes to the brain.

\section{VISUAL DYSFUNCTIONS ASSOCIATED WITH MORPHOLOGICAL CHANGES IN RETINA}

The retina, as mentioned above, consists of different neurons, dendrites, and axons, and it is responsible for integrating response to the visual system to the cortex. Clinically, patients with PD often suffer from various functional disabilities in central, peripheral, or visuoperceptual vision. Although the visual system does not exist in isolation, we focus on the retina in this article and discuss the visual disorders associated with retinal dysfunction (Table 3).

\section{Visual Acuity}

Visual acuity (VA) is an ability to discriminate the details of a stimulus. It has been demonstrated that patients with PD present impaired VA in the prodromal phase of the disease (Jones et al., 1992). Compared with age- and sex-matched healthy people using the standard Snellen chart and computerized test, VA is impaired in individuals with PD. Similarly, Han et al. (2020) confirmed that VA in PD patients was worse than this in control groups. Especially, they also found that the worse VA groups have higher incidence of PD than individuals without visual disability, reflecting the visual disorder is one of the premotor symptoms for PD progression (Han et al., 2020).

Evidence has demonstrated a significant positive correlation between lower visual acuity and thinning RNFL thickness (Satue et al., 2017; Visser et al., 2020; Abd Hamid et al., 2021; Table 3). Sparkly, the thinness in the ganglion cell-inner plexiform layer in PD was strongly correlated with low contrast visual acuity via a comprehensive battery of visual function tests (Murueta-Goyena et al., 2019; Marrocco et al., 2020). Recently, Shi and his colleagues characterized retinal capillary complexity of retina in patients with PD, and found that lower retinal capillary and perfusion densities and capillary complexity was negatively correlated with VA (Shi et al., 2020).

According to the above, dopaminergic neuron cells in retina can release dopamine and contribute to functional VA. 
TABLE 2 | Table outlining the features of native and phosphorylated a-synuclein in the retina.

\begin{tabular}{|c|c|c|c|c|c|}
\hline & Subject & Retinal layers & Morphometric analysis & $\begin{array}{l}\text { Aggregation } \\
\text { propensity or } \\
\text { toxicity }\end{array}$ & References \\
\hline $\begin{array}{l}\text { Native } \\
\text { a-synuclein }\end{array}$ & $\begin{array}{l}\text { Non-PD, } \\
\text { PD patient }\end{array}$ & GCL, IPL, INL & $\begin{array}{l}\text { Soluble a-synuclein, protein } \\
\text { aggregates, Lewy } \\
\text { body/neurite }\end{array}$ & $\pm^{\mathrm{a}}$ & $\begin{array}{l}\text { Guan et al., 2013; } \\
\text { Mailankody et al., 2015; } \\
\text { Robbins et al., } 2021\end{array}$ \\
\hline $\begin{array}{l}\text { Phospho- } \\
\text { a-synuclein }\end{array}$ & PD patient & GCL, IPL, NFL & $\begin{array}{l}\text { Protein aggregates, Lewy } \\
\text { body/neurite }\end{array}$ & $++^{\mathrm{b}}$ & $\begin{array}{l}\text { Archibald et al., 2009; } \\
\text { Schmidt et al., } 2011\end{array}$ \\
\hline
\end{tabular}

Non-PD, healthy control subject; GCL, ganglion cell layer; INL, inner nuclear layer; IPL, inner plexiform layer; NFL, nerve fiber layer.

$a_{ \pm}$: none or low aggregation propensity and toxicity.

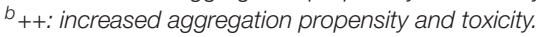

TABLE 3 | Retinal abnormalities in PD patients.

\begin{tabular}{|c|c|c|c|}
\hline Visual abnormality & Morphological changes in Retina & Retinal mechanism defects & References \\
\hline \multirow[t]{3}{*}{ Visual acuity } & RNFL thinning & & $\begin{array}{l}\text { Postuma et al., 2015; Gbd } 2015 \text { Neurological } \\
\text { Disorders Collaborator Group, 2017; Ggbd } 2016 \\
\text { Parkinson's Disease Collaborators, 2018; Santos } \\
\text { Garcia et al., 2019; Xu et al., } 2019\end{array}$ \\
\hline & Loss RGCs & & $\begin{array}{l}\text { Postuma et al., 2015; Gbd } 2015 \text { Neurological } \\
\text { Disorders Collaborator Group, 2017; } \\
\text { Ortuno-Lizaran et al., 2018b }\end{array}$ \\
\hline & Decreased microvascular density & & Ortuno-Lizaran et al., 2018a \\
\hline \multirow[t]{3}{*}{ Contrast sensitivity } & RNFL thinning & $\begin{array}{l}\text { (1)Retinal function in ERGs and VEPs; } \\
\text { (2) Retinal dopaminergic system } \\
\text { impairment and dopamine reduction } \\
\text { (3) Loss of synaptic contacts between } \\
\text { retinal neurons }\end{array}$ & $\begin{array}{l}\text { Ggbd } 2016 \text { Parkinson's Disease Collaborators, } \\
2018\end{array}$ \\
\hline & RGCs loss & & Ortuno-Lizaran et al., 2018b; Kim et al., 2019 \\
\hline & Thinning of foveal neural tissues & & Friedman, 2004; Reddy et al., 2013 \\
\hline Visual hallucinations & RNFL thinning & & Armstrong, 2017; Shi et al., 2020 \\
\hline Color vision & Loss RGCs & & Ortuno-Lizaran et al., 2018b \\
\hline
\end{tabular}

Aggregates of misfolded a-synuclein and related retinal dopamine depletion lead to injury to light-adapted vision and VA. NguyenLegros noted that altered ERGs and VEPs are identical in PD patients and animal models with damaged dopaminergic retinal system (Wong et al., 1985; Olivier et al., 1986; BodisWollner and Tzelepi, 1998; Afsari et al., 2014; Bonilha et al., 2015; Mammadova et al., 2019). In Archibald et al.'s (2011) research, 64 with $\mathrm{PD}, 26$ with $\mathrm{PD}$ dementia (PDD), and 32 normal were evaluated using a series of diagnostic procedures about function on vision, cognition, and related pathology. The study reported the impairments in acuity in patients with PD or PDD, and poorer visual acuity in the last stage of untreated patients (Archibald et al., 2011). Likewise, Richard and his members beat out the correlation between poor VA and the lack of dopamine in the retina, but also the better acuity in $\mathrm{PD}$ patients receiving drugs (Jones et al., 1992).

\section{Contrast Sensitivity}

Contrast sensitivity is a special vision function involving in the regulation of visual resolution ratio and vision at a variety of spatial and light-black frequencies. Patients with diminished vision contrast sensitivity commonly are susceptible to falls, reading problems, and dark-adapted difficulty. In the 1980s, impaired contrast sensitivity was documented in PD patients in comparison with age-matched controls (Regan and Neima, 1984). Since then, an increasing number of studies have consistently offered proof for the impairment of contrast sensitivity in patients with PD (Langheinrich et al., 2000; Silva et al., 2005; Archibald et al., 2009; Armstrong, 2017). Current studies reported by Polo et al. (2016), showed that contrast sensitivity deficit is more common and severe than other visual disorders. Additionally, the impaired contrast sensitivity was associated with $\mathrm{VH}$ and cognitive impairment, as a useful biomarker in patients with PD (Diederich et al., 1998; Ridder et al., 2017).

Like VA, evidence revealed that the inner retinal thinning enhances the presence of contrast sensitivity (Pinkhardt et al., 2020), and the progressive changes in RNFL were associated with progression of abnormal visual function (Satue et al., 2017). Moreover, several studies demonstrated the correlation between impaired vision and remodeled foveal pit, showing the correlation of contrast sensitivity deficit with retinal parafoveal thickness (Miri et al., 2016; Pinkhardt et al., 2020).

In pathological mechanisms, it has been indicated that dopaminergic system impairment in the retina may explain and be partially responsible for the reduced contrast sensitivity in 
patients with PD. Under physiological conditions, the contrast sensitivity and color vision are mainly modulated through D1 and D2 receptors differentially located in the retinal structure. When these receptors lack activation, there are the dispersion of visual signals and alterations in color vision and contrast sensitivity (Hajee et al., 2009). Also, dopamine reduction may result in loss of synaptic contacts with photoreceptor cells and mRGCs and to disturb contrast sensitivity (Hindle et al., 2013; Kaur et al., 2015; Ortuno-Lizaran et al., 2020). Bulens et al. (1987) reported, contrast sensitivity function of 10 patients with $\mathrm{PD}$ before and after levodopa treatment. The remission of contrast sensitivity deficit after the exogenous supplement of dopamine demonstrated the function of the retinal transmitter on the visual pathways. An updated study showed that dopaminergic system impairment and dopamine reduction may be responsible for the reduced contrast sensitivity in PD (Ortuño-Lizarán et al., 2020). In addition, these alterations are linked to loss of dopaminergic synaptic contacts or decline in mRGCs that contribute to circadian rhythm and sleep.

\section{Visual Hallucinations}

Visual hallucination (VH) is a specific feature of $\mathrm{PD}$ compared with other Parkinsonian disorders, accounting for $30-40 \%$ patients with the disease (Onofrj et al., 2007). Clinically, VH manifests various complex symptoms, including flashes of light, visual perception deficit, and color and motion perception impairment. Most studies in patients with $\mathrm{VH}$ demonstrated the disorder was associated with cortical visual discrimination involving in the changes at different visual pathways as well as other neural systems and motor function (Uc et al., 2005). It can explain why VH is also common in cognitive flaw PD patients, and the patients with dementia have the higher prevalence of $\mathrm{VH}$ than patients without dementia (Archibald et al., 2011). However, the underlying pathophysiological mechanisms are still unclear. Based on a hypothesis of VH titled the Charles Bonnet syndrome (Stebbins et al., 2004), we know that retinal damage is linked to poor signals in the brain regions, and lead to less visual cortical activation and play a crucial role in the neuropathophysiological function of VH in PD. Moreover, emerging studies stated that defective visual information processing involvement has been demonstrated in VH of PD patients, so retinal impairment appears to be one of mechanisms of the sign (Visser et al., 2020).

To date a limited number of studies reveals that $\mathrm{VH}$ appears to be associated with inner retinal thinning. Lee et al. (2014) identified RNFL thinning among the PD subgroups, and noted that RNFL thickness is thinnest in groups without dementia, suggesting RNFL thinning was associated with the occurrence of VH in PD. Similarly, a recent report confirmed the relationship between RNFL thinning and the presence of $\mathrm{VH}$, revealing that individuals with $\mathrm{VH}$ had a thinner GCL-IPL than individuals without VH (Visser et al., 2020). It is believed that the old age, disease's duration, motor disorders, and other non-motor disturbances could worsen the $\mathrm{VH}$ as the risk factors in PD (Fénelon et al., 2000; Zhu et al., 2013).

Consistent with visual acuity and contrast sensitivity, retinal pathological changes contribute to the occurrence and development of VH. The dopaminergic system damages have been considered as the pathological basis of VH. Dopamine replacement therapy also supported the evidence for the effects of dopaminergic deficiency on the VH (Onofrj et al., 2002; O'Donnell et al., 2006). Like as the loss of DA, the LB pathology is also associated with the occurrence and progress of VH. Moreover, a number of studies have been proposed to explain $\mathrm{VH}$ in $\mathrm{PD}$, noting that reduced levels of $\gamma$ aminobutyric acid (GABA) are associated with mechanisms of VH (Firbank et al., 2018).

\section{Color Vision}

As is known to all, color vision is the basic function mediated by the photoreceptor cones in the retina and related visual cortex via some specific visual pathways. In the early stages of $\mathrm{PD}$, patients' color vision is impaired and deteriorates with disease duration (Price et al., 1992; Buttner et al., 1995). In the 1990s, scholars assessed the color vision in 35 patients with PD and 26 controls, and reported significant abnormality of color vision in PD compared to the healthy people (Price et al., 1992). Recent studies showed the color detection dysfunction affected movement. For instance, Penedo et al. (2018) reported the ability of obstacle avoidance was impaired due to the impairment of color. Likewise, the axial motor impairments were associated with the changes in color discrimination (Bohnen et al., 2017), suggesting shared pathophysiology between the alteration of color vision and motor or mobility dysfunctions in PD. Additionally, the disorders of visual pathways in PD patients might contribute to the occurrence of poor color vision, such as depressive symptoms (Li et al., 2018), idiopathic rapid eye movement sleep behavior disorder (Postuma et al., 2009), and other different retinal areas.

Likewise, RGCs loss and RNFL thinning may be also causes of impaired color vision in PD (Polo et al., 2016). In an observational cross-sectional study, Polo et al. (2016) evaluated visual dysfunction and its correlation with morphological changes in the retina in participants with $\mathrm{PD}$, and found color vision was associated with most GCL thinning while not significantly correlated between RNFL thickness and other visual dysfunction.

As a pathological hallmark, dopaminergic deficiency in the retina showed an association with the impairment in color vision. In mammalian retinal layers, some dopaminergic receptors are in charge of color vision and contrast sensitivity, so alterations in these functions could be the result of lack of dopaminergic systems (Hajee et al., 2009). In patients with PD, deficiency in color vision influences retinal evoked potentials, reflecting abnormalities in dopaminergic synaptic activity in the retina (Bodis-Wollner et al., 1982). Silva et al. (2005) found color visual deficits within the parvo, Konio, and magnocellular pathways in the retina, especially the parvocellular pathway. Meanwhile, they also found the reduction of dopaminergic neurons around the fovea, suggesting that the dysfunctions of these pathways are possibly related to altered dopaminergic modulation. 
TABLE 4 | Retinal abnormalities in PD animal models.

\begin{tabular}{|c|c|c|c|c|}
\hline Animal & Model & Morphological changes & Retinal defects & References \\
\hline \multirow[t]{2}{*}{ Rat } & Rotenone-induced & $\begin{array}{l}\text { Decreased number of RGCs and DACs; INL and ONL } \\
\text { thinning }\end{array}$ & $\begin{array}{l}\text { Decreased scotopic and photopic a- and b-waves; } \\
\text { Increased b-wave implicit time }\end{array}$ & $\begin{array}{l}\text { Tamer et al., 2005; Onofrj } \\
\text { et al., } 2006\end{array}$ \\
\hline & 6-OHDA-induced & Decreased DA levels & - & Onofrj et al., 2006 \\
\hline \multirow[t]{5}{*}{ Mouse } & MPTP-induced & Decreased number of DACs & Reduced oscillatory potentials, a- and b-waves; & Williams et al., 2008 \\
\hline & Retinal a-Syn overexpression & Decreased number of DACs & $\begin{array}{l}\text { Decrease of light-adapted ERG responses and } \\
\text { visual acuity }\end{array}$ & Guo et al., 2018 \\
\hline & Prnp- A53T- SNCA & Accumulation of $\alpha$-synuclein, loss of photoreceptor cells & & Weil et al., 2016 \\
\hline & TgM83 (A53T $\alpha$-synuclein mutation) & $\begin{array}{l}\text { Accumulation of a-Syn and phosphorylated tau, } \\
\text { decreased number of photoreceptors }\end{array}$ & - & Weil et al., 2016 \\
\hline & DJ-1 knockout & RPE thinning, decreased number of dopamine & Increased amplitude of b-wave and ERG, & Uc et al., 2005 \\
\hline \multirow[t]{2}{*}{ Rabbit } & MPTP-induced & Decreased dopamine level & $\begin{array}{l}\text { Decreased amplitude of b-waves and oscillatory } \\
\text { potentials }\end{array}$ & Bertrand et al., 2012 \\
\hline & 6-OHDA-inducd & Decreased dopamine level & Decreased amplitude of b-waves & Ortuno-Lizaran et al., 2020 \\
\hline \multirow[t]{3}{*}{ Monkey } & MPTP-induced & $\begin{array}{l}\text { Decreased number of DACs, Deteriorated postsynaptic } \\
\text { neurons }\end{array}$ & - & Esteve-Rudd et al., 2011 \\
\hline & MPTP-induced & Decreased number of DACs, RNFL thinning & Abnormal VEP and PERG responses & Willis et al., 2014 \\
\hline & 6-OHDA-inducd & Decreased number of DACs & Abnormal PERG responses & \\
\hline \multirow[t]{2}{*}{ Drosophila } & a-Syn over-expression & - & Decreased PERG responses & Willis, 2005 \\
\hline & LRRK2-G2019S & Loss of photoreceptor function & Decreased ERG response, loss of visual function & $\begin{array}{l}\text { Toscano-Tejeida et al., } \\
\text { 2016; Pineda-Rodriguez } \\
\text { et al., } 2017\end{array}$ \\
\hline
\end{tabular}




\section{FUTURE PERSPECTIVES}

The increasing number of research explores morphological changes associated with retinal dysfunction in $\mathrm{PD}$ as summarized in Table 4. This evidence provides insight into the mechanism underlying visual dysfunctions and retinal changes in PD, mirroring PD brain pathology. Thus, morphological changes or dysfunction in the retina are regarded as a potential approach to diagnosis and monitor Parkinson's disease, and the successful use of the retinal technology in clinical trials is valid and reliable tools to explore neuropathies in the CNS. However, molecular changes and neuropathological mechanisms involved in retinal changes are obscure. More studies are needed to further validate the significance of retinal pathology and vision deficit to establish the causality of these relationships in $\mathrm{PD}$.

\section{REFERENCES}

Abd Hamid, M. R., Wan Hitam, W. H., and Abd Halim, S. (2021). Retinal nerve fiber layer and macular thickness in Parkinson's disease patients. Cureus 13:e16224. doi: 10.7759/cureus.16224

Adam, C. R., Shrier, E., Ding, Y., Glazman, S., and Bodis-Wollner, I. (2013). Correlation of inner retinal thickness evaluated by spectral-domain optical coherence tomography and contrast sensitivity in Parkinson disease. J. Neuroophthalmol. 33, 137-142. doi: 10.1097/WNO.0b013e31828c4e1a

Afsari, F., Christensen, K. V., Smith, G. P., Hentzer, M., Nippe, O. M., Elliott, C. J., et al. (2014). Abnormal visual gain control in a Parkinson's disease model. Hum. Mol. Genet. 23, 4465-4478. doi: 10.1093/hmg/ddu159

Albrecht, P., Muller, A. K., Sudmeyer, M., Ferrea, S., Ringelstein, M., Cohn, E., et al. (2012). Optical coherence tomography in parkinsonian syndromes. PLoS One 7:e34891.

Altintas, O., Iseri, P., Ozkan, B., and Caglar, Y. (2008). Correlation between retinal morphological and functional findings and clinical severity in Parkinson's disease. Doc. Ophthalmol. 116, 137-146. doi: 10.1007/s10633-007-9091-8

Anderson, T. J., and MacAskill, M. R. (2013). Eye movements in patients with neurodegenerative disorders. Nat. Rev. Neurol. 9, 74-85. doi: 10.1038/nrneurol. 2012.273

Archibald, N. K., Clarke, M. P., Mosimann, U. P., and Burn, D. J. (2009). The retina in Parkinson's disease. Brain 132, 1128-1145.

Archibald, N. K., Clarke, M. P., Mosimann, U. P., and Burn, D. J. (2011). Visual symptoms in Parkinson's disease and Parkinson's disease dementia. Mov. Disord. 26, 2387-2395. doi: 10.1002/mds.23891

Armstrong, R. A. (2017). Visual dysfunction in Parkinson's disease. Int. Rev. Neurobiol. 134, 921-946.

Auluck, P. K., Chan, H. Y., Trojanowski, J. Q., Lee, V. M., and Bonini, N. M. (2002). Chaperone suppression of alpha-synuclein toxicity in a Drosophila model for Parkinson's disease. Science 295, 865-868.

Beach, T. G., Carew, J., Serrano, G., Adler, C. H., Shill, H. A., Sue, L. I., et al. (2014). Phosphorylated alpha-synuclein-immunoreactive retinal neuronal elements in Parkinson's disease subjects. Neurosci. Lett. 571, 34-38. doi: 10.1016/j.neulet. 2014.04.027

Bertrand, J. A., Bedetti, C., Postuma, R. B., Monchi, O., Genier Marchand, D., Jubault, T., et al. (2012). Color discrimination deficits in Parkinson's disease are related to cognitive impairment and white-matter alterations. Mov. Disord. 27, 1781-1788. doi: 10.1002/mds.25272

Biehlmaier, O., Alam, M., and Schmidt, W. J. (2007). A rat model of Parkinsonism shows depletion of dopamine in the retina. Neurochem. Int. 50, 189-195. doi: 10.1016/j.neuint.2006.08.001

Bodis-Wollner, I. (1990). Visual deficits related to dopamine deficiency in experimental animals and Parkinson's disease patients. Trends Neurosci. 13, 296-302. doi: 10.1016/0166-2236(90)90113-o

Bodis-Wollner, I. (2009). Retinopathy in parkinson disease. J. Neural. Transm. (Vienna) 116, 1493-1501. doi: 10.1007/s00702-009-0292-z

\section{AUTHOR CONTRIBUTIONS}

TT and YY conceived the conception and design of the manuscript. YZ drafted the manuscript. TT was responsible for the revision of the article. $\mathrm{YZ}$ and $\mathrm{XZ}$ participated in the discussion about the article. All authors read and approved the final manuscript.

\section{FUNDING}

This study was supported by funds from the National Natural Science Foundation of China (Grant No. U1804171), the Shanghai Sailing Program (20YF1444800), and the Shanghai Municipal Planning Commission of Science and Research Fund (20204Y0123).

Bodis-Wollner, I., and Tzelepi, A. (1998). The push-pull action of dopamine on spatial tuning of the monkey retina: the effects of dopaminergic deficiency and selective D1 and D2 receptor ligands on the pattern electroretinogram. Vis. Res. 38, 1479-1487. doi: 10.1016/s0042-6989(98)00028-5

Bodis-Wollner, I., Kozlowski, P. B., Glazman, S., and Miri, S. (2014b). $\alpha$-synuclein in the inner retina in parkinson disease. Ann. Neurol. 75, 964-966. doi: 10.1002/ ana.24182

Bodis-Wollner, I., Marx, M. S., Mitra, S., Bobak, P., Mylin, L., and Yahr, M. (1987). Visual dysfunction in Parkinson's disease. Loss in spatiotemporal contrast sensitivity. Brain 110 (Pt 6), 1675-1698. doi: 10.1093/brain/110.6. 1675

Bodis-Wollner, I., Miri, S., and Glazman, S. (2014a). Venturing into the no-man's land of the retina in Parkinson's disease. Mov. Disord. 29, 15-22. doi: 10.1002/ mds. 25741

Bodis-Wollner, I., Yahr, M. D., Mylin, L., and Thornton, J. (1982). Dopaminergic deficiency and delayed visual evoked potentials in humans. Ann. Neurol. 11, 478-483. doi: 10.1002/ana.410110507

Bohnen, N., Haugen, J., Ridder, A., Kotagal, V., Albin, R., Frey, K., et al. (2017). Color discrimination errors associate with axial motor impairments in Parkinson's disease. Mov. Disord. Clin. Pract. 4, 864-869. doi: 10.1002/mdc3. 12527

Bonilha, V. L., Bell, B. A., Rayborn, M. E., Yang, X., Kaul, C., Grossman, G. H., et al. (2015). Loss of DJ-1 elicits retinal abnormalities, visual dysfunction, and increased oxidative stress in mice. Exp. Eye Res. 139, 22-36. doi: 10.1016/j.exer. 2015.07.014

Breydo, L., Wu, J. W., and Uversky, V. N. (2012). Alpha-synuclein misfolding and Parkinson's disease. Biochim. Biophys. Acta 1822, 261-285.

Bulens, C., Meerwaldt, J. D., Van der Wildt, G. J., and Van Deursen, J. B. (1987). Effect of levodopa treatment on contrast sensitivity in Parkinson's disease. Ann. Neurol. 22, 365-369. doi: 10.1002/ana.410220313

Burre, J., Sharma, M., Tsetsenis, T., Buchman, V., Etherton, M. R., and Sudhof, T. C. (2010). Alpha-synuclein promotes SNARE-complex assembly in vivo and in vitro. Science 329, 1663-1667. doi: 10.1126/science.1195227

Buttner, T., Kuhn, W., Muller, T., Patzold, T., Heidbrink, K., and Przuntek, H. (1995). Distorted color discrimination in 'de novo' parkinsonian patients. Neurology 45, 386-387. doi: 10.1212/wnl.45.2.386

Cameron, J. R., Megaw, R. D., Tatham, A. J., McGrory, S., MacGillivray, T. J., Doubal, F. N., et al. (2017). Lateral thinking - Interocular symmetry and asymmetry in neurovascular patterning, in health and disease. Prog. Retin. Eye Res. 59, 131-157. doi: 10.1016/j.preteyeres.2017.04.003

Cameron, M. A., Pozdeyev, N., Vugler, A. A., Cooper, H., Iuvone, P. M., and Lucas, R. J. (2009). Light regulation of retinal dopamine that is independent of melanopsin phototransduction. Eur. J. Neurosci. 29, 761-767. doi: 10.1111/j. 1460-9568.2009.06631.x

Cohen, A. I., Todd, R. D., Harmon, S., and O’Malley, K. L. (1992). Photoreceptors of mouse retinas possess D4 receptors coupled to adenylate cyclase. Proc. Natl. Acad. Sci. U. S. A. 89, 12093-12097. doi: 10.1073/pnas.89.24.12093 
Cubo, E., Tedejo, R. P., Rodriguez Mendez, V., Lopez Pena, M. J., and Trejo Gabriel, Y. G. J. M. (2010). Retina thickness in Parkinson's disease and essential tremor. Mov. Disord. 25, 2461-2462. doi: 10.1002/mds.23215

Cuenca, N., Herrero, M. T., Angulo, A., de Juan, E., Martinez-Navarrete, G. C., Lopez, S., et al. (2005). Morphological impairments in retinal neurons of the scotopic visual pathway in a monkey model of Parkinson's disease. J. Comp. Neurol. 493, 261-273. doi: 10.1002/cne.20761

Diederich, N. J., Goetz, C. G., Raman, R., Pappert, E. J., Leurgans, S., and Piery, V. (1998). Poor visual discrimination and visual hallucinations in Parkinson's disease. Clin. Neuropharmacol. 21, 289-295.

Diederich, N. J., Stebbins, G., Schiltz, C., and Goetz, C. G. (2014). Are patients with Parkinson's disease blind to blindsight? Brain 137, 1838-1849. doi: 10.1093/ brain/awu094

Elabi, O., Gaceb, A., Carlsson, R., Padel, T., Soylu-Kucharz, R., Cortijo, I., et al. (2021). Human alpha-synuclein overexpression in a mouse model of Parkinson's disease leads to vascular pathology, blood brain barrier leakage and pericyte activation. Sci Rep 11:1120. doi: 10.1038/s41598-020-80889-8

Esteve-Rudd, J., Fernandez-Sanchez, L., Lax, P., De Juan, E., Martin-Nieto, J., and Cuenca, N. (2011). Rotenone induces degeneration of photoreceptors and impairs the dopaminergic system in the rat retina. Neurobiol. Dis. 44, 102-115. doi: 10.1016/j.nbd.2011.06.009

Farooq, S. M., and Ashour, H. M. (2013). Eye-mediated induction of specific immune tolerance to encephalitogenic antigens. CNS Neurosci. Ther. 19, 503510. doi: $10.1111 / \mathrm{cns} .12087$

Fénelon, G., Mahieux, F., Huon, R., and Ziégler, M. (2000). Hallucinations in Parkinson's disease: prevalence, phenomenology and risk factors. Brain $123(\mathrm{Pt}$ 4), 733-745. doi: 10.1093/brain/123.4.733

Fercher, A. F., Hitzenberger, C. K., Drexler, W., Kamp, G., and Sattmann, H. (1993). In vivo optical coherence tomography. Am. J. Ophthalmol. 116, 113-114.

Firbank, M. J., Parikh, J., Murphy, N., Killen, A., Allan, C. L., Collerton, D., et al. (2018). Reduced occipital GABA in Parkinson disease with visual hallucinations. Neurology 91, e675-e685. doi: 10.1212/WNL. 0000000000006007

Frederick, J. M., Rayborn, M. E., Laties, A. M., Lam, D. M., and Hollyfield, J. G. (1982). Dopaminergic neurons in the human retina. J Comp. Neurol. 210, 65-79. doi: $10.1002 /$ cne. 902100108

Friedman, J. H. (2004). Ophthalmologic features of Parkinson's disease. Neurology 63, 940-1; authorrely940-1.

Fujimoto, J., and Swanson, E. (2016). The development, commercialization, and impact of optical coherence tomography. Invest. Ophthalmol. Vis. Sci. 57, OCT1-OCT13. doi: 10.1167/iovs.16-19963

Garcia-Martin, E., Larrosa, J., Polo, V., Satue, M., Marques, M., Alarcia, R., et al. (2014a). Distribution of retinal layer atrophy in patients with Parkinson disease and association with disease severity and duration. Am. J. Ophthalmol. 157, 470-478.e2.

Garcia-Martin, E., Rodriguez-Mena, D., Satue, M., Almarcegui, C., Dolz, I., Alarcia, R., et al. (2014b). Electrophysiology and optical coherence tomography to evaluate Parkinson disease severity. Invest. Ophthalmol. Vis. Sci. 55, 696-705. doi: 10.1167/iovs.13-13062

Gbd 2015 Neurological Disorders Collaborator Group (2017). Global, regional, and national burden of neurological disorders during 1990-2015: a systematic analysis for the Global Burden of Disease Study 2015. Lancet Neurol. 16, 877-897.

Ge, Y., Xu, W., Ou, Y., Qu, Y., Ma, Y., Huang, Y., et al. (2021). Retinal biomarkers in Alzheimer's disease and mild cognitive impairment: a systematic review and meta-analysis. Ageing Res. Rev. 69:101361. doi: 10.1016/j.arr.2021.101361

Ggbd 2016 Parkinson's Disease Collaborators (2018). Global, regional, and national burden of Parkinson's disease, 1990-2016: a systematic analysis for the Global Burden of Disease Study 2016. Lancet Neurol. 17, 939-953. doi: 10.1016/S14744422(18)30295-3

Giordano, N., Iemolo, A., Mancini, M., Cacace, F., De Risi, M., Latagliata, E. C., et al. (2018). Motor learning and metaplasticity in striatal neurons: relevance for Parkinson's disease. Brain 141, 505-520. doi: 10.1093/brain/aw x351

Guan, J., Pavlovic, D., Dalkie, N., Waldvogel, H. J., O’Carroll, S. J., Green, C. R., et al. (2013). Vascular degeneration in Parkinson's disease. Brain Pathol. 23, 154-164. doi: 10.1111/j.1750-3639.2012.00628.x
Güler, A., Ecker, J., Lall, G., Haq, S., Altimus, C., Liao, H., et al. (2008). Melanopsin cells are the principal conduits for rod-cone input to non-image-forming vision. Nature 453, 102-105. doi: 10.1038/nature06829

Gulmez Sevim, D., Unlu, M., Sonmez, S., Gultekin, M., Karaca, C., and Ozturk Oner, A. (2019). Retinal vessel diameter obtained by optical coherence tomography is spared in Parkinson's disease. Int. Ophthalmol. 39, 813-819. doi: 10.1007/s10792-018-0873-7

Guo, L., Normando, E. M., Shah, P. A., De Groef, L., and Cordeiro, M. F. (2018). Oculo-visual abnormalities in Parkinson's disease: Possible value as biomarkers. Mov. Disord. 33, 1390-1406. doi: 10.1002/mds.27454

Ha Usler, G., and Lindner, M. W. (1998). "Coherence radar" and "spectral radar"new tools for dermatological diagnosis. J. Biomed. Opt. 3, 21-31. doi: 10.1117/ 1.429899

Hajee, M. E., March, W. F., Lazzaro, D. R., Wolintz, A. H., Shrier, E. M., Glazman, S., et al. (2009). Inner retinal layer thinning in Parkinson disease. Arch. Ophthalmol. 127, 737-741. doi: 10.1001/archophthalmol.2009.106

Hampson, E. C., Vaney, D. I., and Weiler, R. (1992). Dopaminergic modulation of gap junction permeability between amacrine cells in mammalian retina. J. Neurosci. 12, 4911-4922. doi: 10.1523/JNEUROSCI.12-12-04911. 1992

Han, G., Han, J., Han, K., Youn, J., Chung, T., and Lim, D. (2020). Visual acuity and development of parkinson's disease: a nationwide cohort study. Mov. Disord. 35, 1532-1541. doi: $10.1002 / \mathrm{mds} .28184$

Hanuska, J., Bonnet, C., Rusz, J., Sieger, T., Jech, R., Rivaud-Pechoux, S., et al. (2015). Fast vergence eye movements are disrupted in Parkinson's disease: a video-oculography study. Parkinsonism Relat. Disord. 21, 797-799. doi: 10. 1016/j.parkreldis.2015.04.014

Harnois, C., and Di Paolo, T. (1990). Decreased dopamine in the retinas of patients with Parkinson's disease. Invest. Ophthalmol. Vis. Sci. 31, 2473-2475.

Hasanov, S., Demirkilinc Biler, E., Acarer, A., Akkin, C., Colakoglu, Z., and Uretmen, O. (2019). Functional and morphological assessment of ocular structures and follow-up of patients with early-stage Parkinson's disease. Int. Ophthalmol. 39, 1255-1262. doi: 10.1007/s10792-018-0934-y

Hattar, S., Liao, H., Takao, M., Berson, D., and Yau, K. (2002). Melanopsincontaining retinal ganglion cells: architecture, projections, and intrinsic photosensitivity. Science (New York, N.Y.) 295, 1065-1070. doi: 10.1126/science. 1069609

Henchcliffe, C., and Beal, M. F. (2008). Mitochondrial biology and oxidative stress in Parkinson disease pathogenesis. Nat. Clin. Pract. Neurol. 4, 600-609. doi: 10.1038/ncpneuro0924

Henderson, A., Trip, S., Schlottmann, P., Altmann, D., Garway-Heath, D., Plant, G., et al. (2008). An investigation of the retinal nerve fibre layer in progressive multiple sclerosis using optical coherence tomography. Brain 131, 277-287. doi: 10.1093/brain/awm285

Hillman, D. W., Lin, D., and Burnside, B. (1995). Evidence for D4 receptor regulation of retinomotor movement in isolated teleost cone inner-outer segments. J. Neurochem. 64, 1326-1335. doi: 10.1046/j.1471-4159.1995. 64031326.x

Hindle, S., Afsari, F., Stark, M., Middleton, C. A., Evans, G. J., Sweeney, S. T., et al. (2013). Dopaminergic expression of the Parkinsonian gene LRRK2-G2019S leads to non-autonomous visual neurodegeneration, accelerated by increased neural demands for energy. Hum. Mol. Genet. 22, 2129-2140. doi: 10.1093/ hmg/ddt061

Huang, D., Wang, J., Lin, C. P., Puliafito, C. A., and Fujimoto, J. G. (1991). Micronresolution ranging of cornea anterior chamber by optical reflectometry. Lasers Surg. Med. 11, 419-425. doi: 10.1002/lsm.1900110506

Hughes, A. D., Falaschetti, E., Witt, N., Wijetunge, S., Thom, S. A., Tillin, T., et al. (2016). Association of retinopathy and retinal microvascular abnormalities with stroke and cerebrovascular disease. Stroke 47, 2862-2864. doi: 10.1161/ STROKEAHA.116.014998

Inzelberg, R., Ramirez, J. A., Nisipeanu, P., and Ophir, A. (2004). Retinal nerve fiber layer thinning in Parkinson disease. Vis. Res. 44, 2793-2797. doi: 10.1016/ j.visres.2004.06.009

Iwai, A., Masliah, E., Yoshimoto, M., Ge, N., Flanagan, L., de Silva, H. A., et al. (1995). The precursor protein of non-A beta component of Alzheimer's disease amyloid is a presynaptic protein of the central nervous system. Neuron 14, 467-475. 
Jain, S., Siegle, G. J., Gu, C., Moore, C. G., Ivanco, L. S., Studenski, S., et al. (2011). Pupillary unrest correlates with arousal symptoms and motor signs in Parkinson disease. Mov. Disord. 26, 1344-1347. doi: 10.1002/mds.23628

Jimenez, B., Ascaso, F. J., Cristobal, J. A., and Lopez del Val, J. (2014). Development of a prediction formula of Parkinson disease severity by optical coherence tomography. Mov. Disord. 29, 68-74.

Jiménez, B., Ascaso, F., Cristóbal, J., and López del Val, J. (2014). Development of a prediction formula of Parkinson disease severity by optical coherence tomography. Mov. Disord. 29, 68-74. doi: 10.1002/mds.25747

Jones, R. D., Donaldson, I. M., and Timmings, P. L. (1992). Impairment of highcontrast visual acuity in Parkinson's disease. Mov. Disord. 7, 232-238. doi: 10.1002/mds. 870070308

Kahle, P. J., Neumann, M., Ozmen, L., Muller, V., Odoy, S., Okamoto, N., et al. (2001). Selective insolubility of alpha-synuclein in human Lewy body diseases is recapitulated in a transgenic mouse model. Am. J. pathol. 159, 2215-2225. doi: 10.1016/s0002-9440(10)63072-6

Kaur, M., Saxena, R., Singh, D., Behari, M., Sharma, P., and Menon, V. (2015). Correlation between structural and functional retinal changes in parkinson disease. J. Neuroophthalmol. 35, 254-258. doi: 10.1097/WNO. 0000000000000240

Kim, S., Kwon, S. H., Kam, T. I., Panicker, N., Karuppagounder, S. S., Lee, S., et al. (2019). Transneuronal propagation of pathologic alpha-synuclein from the gut to the brain models Parkinson's disease. Neuron 62:e7. doi: 10.1016/j.neuron. 2019.05.035

Kirbas, S., Turkyilmaz, K., Tufekci, A., and Durmus, M. (2013). Retinal nerve fiber layer thickness in Parkinson disease. J. Neuro Ophthalmol. 33, 62-65. doi: 10.1097/wno.0b013e3182701745

Klettner, A., Richert, E., Kuhlenbaumer, G., Nolle, B., Bhatia, K. P., Deuschl, G., et al. (2016). Alpha synuclein and crystallin expression in human lens in Parkinson's disease. Mov .Disord. 31, 600-601. doi: 10.1002/mds.26557

Koens, L. H., Tijssen, M. A. J., Lange, F., Wolffenbuttel, B. H. R., Rufa, A., Zee, D. S., et al. (2018). Eye movement disorders and neurological symptoms in lateonset inborn errors of metabolism. Mov. Disord. 33, 1844-1856. doi: 10.1002/ mds. 27484

Kwapong, W. R., Ye, H., Peng, C., Zhuang, X., Wang, J., Shen, M., et al. (2018). Retinal microvascular impairment in the early stages of Parkinson's disease. Invest. Ophthalmol. Vis. Sci. 59, 4115-4122. doi: 10.1167/iovs.17-23230

La Morgia, C., Barboni, P., Rizzo, G., Carbonelli, M., Savini, G., Scaglione, C., et al. (2013). Loss of temporal retinal nerve fibers in Parkinson disease: a mitochondrial pattern? Eur. J. Neurol. 20, 198-201. doi: 10.1111/j.1468-1331. 2012.03701.x

Lai, S. W., Lin, C. L., Liao, K. F., and Chang-Ou, K. C. (2015). Increased risk of Parkinson's disease in cataract patients: a population-based cohort study. Parkinsonism Relat. Disord. 21, 68-71. doi: 10.1016/j.parkreldis.2014.11.005

Langheinrich, T., Tebartz van Elst, L., Lagreze, W. A., Bach, M., Lucking, C. H., and Greenlee, M. W. (2000). Visual contrast response functions in Parkinson's disease: evidence from electroretinograms, visually evoked potentials and psychophysics. Clin. Neurophysiol. 111, 66-74. doi: 10.1016/s1388-2457(99) 00223-0

Langwinska-Wosko, E., Litwin, T., Szulborski, K., and Czlonkowska, A. (2016). Optical coherence tomography and electrophysiology of retinal and visual pathways in Wilson's disease. Metab. Brain Dis. 31, 405-415. doi: 10.1007/ s11011-015-9776-8

Lee, J. Y., Kim, J. M., Ahn, J., Kim, H. J., Jeon, B. S., and Kim, T. W. (2014). Retinal nerve fiber layer thickness and visual hallucinations in Parkinson's disease. Mov. Disord. 29, 61-67. doi: 10.1002/mds. 25543

Li, D., Liu, F., Chen, K., Bu, L., Yang, K., Chen, C., et al. (2018). Depressive symptoms are associated with color vision but not olfactory function in patients with Parkinson's disease. J. Neuropsychiatry Clin. Neurosci. 30, 122-129. doi: 10.1176/appi.neurospych.17030063

Li, Z., and Tian, T. (2017). Light therapy promoting dopamine release by stimulating retina in parkinson disease. JAMA Neurol. 74, 1267-1268.

Liu, C. W., Giasson, B. I., Lewis, K. A., Lee, V. M., Demartino, G. N., and Thomas, P. J. (2005). A precipitating role for truncated alpha-synuclein and the proteasome in alpha-synuclein aggregation: implications for pathogenesis of Parkinson disease. J. Biol. Chem. 280, 22670-22678. doi: 10.1074/jbc. M501508200
London, A., Benhar, I., and Schwartz, M. (2013). The retina as a window to the brain-from eye research to CNS disorders. Nat. Rev. Neurol. 9, 44-53. doi: 10.1038/nrneurol.2012.227

Ma, L. J., Xu, L. L., Mao, C. J., Fu, Y. T., Ji, X. Y., Shen, Y., et al. (2018). Progressive Changes in the Retinal Structure of Patients with Parkinson's Disease. J. Parkinsons Dis. 8, 85-92. doi: 10.3233/JPD-171184

MacAskill, M. R., and Anderson, T. J. (2016). Eye movements in neurodegenerative diseases. Curr. Opin. Neurol. 29, 61-68. doi: 10.1097/WCO.0000000000000274

Mailankody, P., Battu, R., Khanna, A., Lenka, A., Yadav, R., and Pal, P. K. (2015). Optical coherence tomography as a tool to evaluate retinal changes in Parkinson's disease. Parkinsonism Relat. Disord. 21, 1164-1169. doi: 10.1016/j. parkreldis.2015.08.002

Malmfors, T. (1963). Evidence of adrenergic. Acta Physiol. Scand. 58, 99-100.

Mammadova, N., Summers, C. M., Kokemuller, R. D., He, Q., Ding, S., Baron, T., et al. (2019). Accelerated accumulation of retinal alpha-synuclein (pSer129) and tau, neuroinflammation, and autophagic dysregulation in a seeded mouse model of Parkinson's disease. Neurobiol. Dis. 121, 1-16. doi: 10.1016/j.nbd.2018. 09.013

Marrocco, E., Indrieri, A., Esposito, F., Tarallo, V., Carboncino, A., Alvino, F. G., et al. (2020). alpha-synuclein overexpression in the retina leads to vision impairment and degeneration of dopaminergic amacrine cells. Sci. Rep. 10:9619. doi: 10.1038/s41598-020-66497-6

Meng, T., Zheng, Z. H., Liu, T. T., and Lin, L. (2012). Contralateral retinal dopamine decrease and melatonin increase in progression of hemiparkinsonium rat. Neurochem. Res. 37, 1050-1056. doi: 10.1007/s11064012-0706-4

Miri, S., Glazman, S., Mylin, L., and Bodis-Wollner, I. (2016). A combination of retinal morphology and visual electrophysiology testing increases diagnostic yield in Parkinson's disease. Parkinsonism Relat. Disord. 22 (Suppl 1), S134S137. doi: 10.1016/j.parkreldis.2015.09.015

Moschos, M. M., Tagaris, G., Markopoulos, I., Margetis, I., Tsapakis, S., Kanakis, M., et al. (2011). Morphologic changes and functional retinal impairment in patients with Parkinson disease without visual loss. Eur. J. Ophthalmol. 21, 24-29. doi: 10.5301/ejo.2010.1318

Murueta-Goyena, A., Del Pino, R., Reyero, P., Galdos, M., Arana, B., LucasJimenez, O., et al. (2019). Parafoveal thinning of inner retina is associated with visual dysfunction in Lewy body diseases. Mov. Disord. 34, 1315-1324.

Netser, R., Demmin, D. L., Dobkin, R., Goldstein, A., Roche, M., Netser Zernik, A., et al. (2021). Flash electroretinography parameters and Parkinson's disease. J. Parkinsons Dis. 11, 251-259. doi: 10.3233/JPD-191830

Nguyen-Legros, J. (1988). Functional neuroarchitecture of the retina: hypothesis on the dysfunction of retinal dopaminergic circuitry in Parkinson's disease. Surg. Radiol. Anat. 10, 137-144. doi: 10.1007/BF02307822

Normando, E. M., Davis, B. M., De Groef, L., Nizari, S., Turner, L. A., Ravindran, N., et al. (2016). The retina as an early biomarker of neurodegeneration in a rotenone-induced model of Parkinson's disease: evidence for a neuroprotective effect of rosiglitazone in the eye and brain. Acta Neuropathol. Commun. 4:86. doi: 10.1186/s40478-016-0346-z

Nunes, A., Silva, G., Duque, C., Januario, C., Santana, I., Ambrosio, A. F., et al. (2019). Retinal texture biomarkers may help to discriminate between Alzheimer's, Parkinson's, and healthy controls. PLoS One 14:e0218826. doi: 10.1371/journal.pone.0218826

O’Donnell, B. F., Bismark, A., Hetrick, W. P., Bodkins, M., Vohs, J. L., and Shekhar, A. (2006). Early stage vision in schizophrenia and schizotypal personality disorder. Schizophr. Res. 86, 89-98. doi: 10.1016/j.schres.2006.05.016

Olivier, P., Jolicoeur, F. B., Lafond, G., Drumheller, A. L., and Brunette, J. R. (1986). Dose related effects of 6-OHDA on rabbit retinal dopamine concentrations and ERG B-wave amplitudes. Brain Res. Bull. 16, 751-753. doi: 10.1016/03619230(86)90148-6

Onofrj, M., Bonanni, L., Albani, G., Mauro, A., Bulla, D., and Thomas, A. (2006). Visual hallucinations in Parkinson's disease: clues to separate origins. J. Neurol. Sci. 248, 143-150. doi: 10.1016/j.jns.2006.05.025

Onofrj, M., Thomas, A., and Bonanni, L. (2007). New approaches to understanding hallucinations in Parkinson's disease: phenomenology and possible origins. Expert Rev. Neurother. 7, 1731-1750. doi: 10.1586/14737175.7.12.1731

Onofrj, M., Thomas, A., D’Andreamatteo, G., Iacono, D., Luciano, A., Di Rollo, A., et al. (2002). Incidence of RBD and hallucination in patients affected by 
Parkinson's disease: 8-year follow-up. Neurol. Sci. 23 (Suppl 2), S91-S94. doi: $10.1007 / \mathrm{s} 100720200085$

Ortuño-Lizarán, I., ánchez-Sáez, X. S., Lax, P., Serrano, G., Beach, T., Adler, C., et al. (2020). Dopaminergic retinal cell loss and visual dysfunction in parkinson disease. Ann. Neurol. 88, 893-906. doi: 10.1002/ana.25897

Ortuno-Lizaran, I., Beach, T. G., Serrano, G. E., Walker, D. G., Adler, C. H., and Cuenca, N. (2018a). Phosphorylated alpha-synuclein in the retina is a biomarker of Parkinson's disease pathology severity. Mov. Disord. 33, 13151324. doi: $10.1002 / \mathrm{mds} .27392$

Ortuno-Lizaran, I., Esquiva, G., Beach, T. G., Serrano, G. E., Adler, C. H., Lax, P., et al. (2018b). Degeneration of human photosensitive retinal ganglion cells may explain sleep and circadian rhythms disorders in Parkinson's disease. Acta Neuropathol. Commun. 6:90. doi: 10.1186/s40478-018-0596-z

Ortuno-Lizaran, I., Sanchez-Saez, X., Lax, P., Serrano, G. E., Beach, T. G., Adler, C. H., et al. (2020). Dopaminergic retinal cell loss and visual dysfunction in parkinson disease. Ann. Neurol. 88, 893-906.

Pavlenko, T. A., Kim, A. R., Kurina, A. Y., Davydova, N. G., Kolomojceva, E. M., Chesnokova, N. B., et al. (2018). [Endothelins and dopamine levels in tears for assessment of neurovascular disorders in glaucoma]. Vestn. Oftalmol. 134, 41-46. doi: 10.17116/oftalma201813404141

Penedo, T., Polastri, P., Rodrigues, S., Simieli, L., Baptista, A., Moretto, G., et al. (2018). Influence of obstacle color on locomotor and gaze behaviors during obstacle avoidance in people with Parkinson's disease. Exp. Brain Res. 236, 3319-3325. doi: 10.1007/s00221-018-5385-1

Pilat, A., McLean, R. J., Proudlock, F. A., Maconachie, G. D., Sheth, V., Rajabally, Y. A., et al. (2016). In vivo morphology of the optic nerve and retina in patients with Parkinson's disease. Invest. Ophthalmol. Vis. Sci. 57, 4420-4427. doi: $10.1167 /$ iovs.16-20020

Pineda-Rodriguez, B., Toscano-Tejeida, D., Garcia-Vences, E., Rodriguez-Barrera, R., Flores-Romero, A., Castellanos-Canales, D., et al. (2017). Anterior chamber associated immune deviation used as a neuroprotective strategy in rats with spinal cord injury. PLoS One 12:e0188506. doi: 10.1371/journal.pone.01 88506

Pinkhardt, E. H., Ding, Y., Slotnick, S., Kassubek, J., Ludolph, A. C., Glazman, S., et al. (2020). The intrinsically restructured fovea is correlated with contrast sensitivity loss in Parkinson's disease. J. Neural. Transm. (Vienna) 127, 12751283. doi: 10.1007/s00702-020-02224-9

Polo, V., Satue, M., Rodrigo, M. J., Otin, S., Alarcia, R., Bambo, M. P., et al. (2016). Visual dysfunction and its correlation with retinal changes in patients with Parkinson's disease: an observational cross-sectional study. BMJ Open 6:e009658. doi: 10.1136/bmjopen-2015-009658

Popova, E. (2014). Role of dopamine in distal retina. J. Comp. Physiol. A Neuroethol. Sens Neural. Behav. Physiol. 200, 333-358. doi: 10.1007/s00359-014-0906-2

Postuma, R. B., Berg, D., Stern, M., Poewe, W., Olanow, C. W., Oertel, W., et al. (2015). MDS clinical diagnostic criteria for Parkinson's disease. Mov. Disord. 30, 1591-1601. doi: 10.1002/mds.26424

Postuma, R., Gagnon, J., Vendette, M., and Montplaisir, J. Y. (2009). Markers of neurodegeneration in idiopathic rapid eye movement sleep behaviour disorder and Parkinson's disease. Brain 132, 3298-3307. doi: 10.1093/brain/awp244

Price, M. J., Feldman, R. G., Adelberg, D., and Kayne, H. (1992). Abnormalities in color vision and contrast sensitivity in Parkinson's disease. Neurology 42, 887-890. doi: 10.1212/wnl.42.4.887

Reddy, V. C., Patel, S. V., Hodge, D. O., and Leavitt, J. A. (2013). Corneal sensitivity, blink rate, and corneal nerve density in progressive supranuclear palsy and Parkinson disease. Cornea 32, 631-635. doi: 10.1097/ICO.0b013e31825 74ade

Regan, D., and Neima, D. (1984). Visual fatigue and visual evoked potentials in multiple sclerosis, glaucoma, ocular hypertension and Parkinson's disease. J. Neurol. Neurosurg. Psychiatry 47, 673-678. doi: 10.1136/jnnp.47.7.673

Ridder, A., Muller, M. L., Kotagal, V., Frey, K. A., Albin, R. L., and Bohnen, N. I. (2017). Impaired contrast sensitivity is associated with more severe cognitive impairment in Parkinson disease. Parkinsonism Relat. Disord. 34, 15-19. doi: 10.1016/j.parkreldis.2016.10.006

Robbins, C. B., Thompson, A. C., Bhullar, P. K., Koo, H. Y., Agrawal, R., Soundararajan, S., et al. (2021). Characterization of Retinal Microvascular and Choroidal Structural Changes in Parkinson Disease. JAMA Ophthalmol. 139, 182-188. doi: 10.1001/jamaophthalmol.2020.5730
Santos Garcia, D., de Deus Fonticoba, T., Suarez Castro, E., Borrue, C., Mata, M., Solano Vila, B., et al. (2019). Non-motor symptoms burden, mood, and gait problems are the most significant factors contributing to a poor quality of life in non-demented Parkinson's disease patients: Results from the COPPADIS Study Cohort. Parkinsonism Relat. Disord. 66, 151-157. doi: 10.1016/j.parkreldis.2019. 07.031

Satue, M., Rodrigo, M. J., Obis, J., Vilades, E., Gracia, H., Otin, S., et al. (2017). Evaluation of progressive visual dysfunction and retinal degeneration in patients with Parkinson's disease. Invest. Ophthalmol. Vis. Sci. 58, 1151-1157. doi: 10.1167/iovs.16-20460

Schmidt, T. M., Do, M. T., Dacey, D., Lucas, R., Hattar, S., and Matynia, A. (2011). Melanopsin-positive intrinsically photosensitive retinal ganglion cells: from form to function. J. Neurosci. 31, 16094-16101. doi: 10.1523/JNEUROSCI. 4132-11.2011

Seiple, W., Jennings, D., Rosen, R. B., Borchert, L., Canale, L., Fagan, N., et al. (2016). Ophthalmologic baseline characteristics and 2-year ophthalmologic safety profile of pramipexole ir compared with ropinirole ir in patients with early Parkinson's disease. Parkinsons Dis. 2016:8298503. doi: 10.1155/2016/ 8298503

Shi, C., Chen, Y., Kwapong, W. R., Tong, Q., Wu, S., Zhou, Y., et al. (2020). Characterization by fractal dimension analysis of the retinal capillary network in parkinson disease. Retina 40, 1483-1491. doi: 10.1097/IAE. 0000000000002641

Shrier, E. M., Adam, C. R., Spund, B., Glazman, S., and Bodis-Wollner, I. (2012). Interocular asymmetry of foveal thickness in Parkinson disease. J. Ophthalmol. 2012:728457. doi: $10.1155 / 2012 / 728457$

Silva, M. F., Faria, P., Regateiro, F. S., Forjaz, V., Januario, C., Freire, A., et al. (2005). Independent patterns of damage within magno-, parvo- and koniocellular pathways in Parkinson's disease. Brain 128, 2260-2271.

Stebbins, G., Goetz, C., Carrillo, M., Bangen, K., Turner, D., Glover, G., et al. (2004). Altered cortical visual processing in PD with hallucinations: an fMRI study. Neurology 63, 1409-1416. doi: 10.1212/01.wnl.0000141853.27081.bd

Stenc Bradvica, I., Bradvica, M., Matic, S., and Reisz-Majic, P. (2015). Visual dysfunction in patients with Parkinson's disease and essential tremor. Neurol. Sci. 36, 257-262. doi: 10.1007/s10072-014-1930-2

Streilein, J. W. (2003). Ocular immune privilege: therapeutic opportunities from an experiment of nature. Nat. Rev. Immunol. 3, 879-889. doi: 10.1038/nri1224

Swanson, E. A., Izatt, J. A., Hee, M. R., Huang, D., Lin, C. P., Schuman, J. S., et al. (1993). In vivo retinal imaging by optical coherence tomography. Opt. Lett. 18, 1864-1866.

Takatsuna, Y., dachi-Usami, E. A., Ino, H., and Chiba, T. (1992). [Effects of MPTP on the mouse retina]. Nippon Ganka Gakkai Zasshi 96, 767-775.

Tamer, C., Melek, I. M., Duman, T., and Oksuz, H. (2005). Tear film tests in Parkinson's disease patients. Ophthalmology 112:1795.

Toscano-Tejeida, D., Ibarra, A., Phillips-Farfan, B. V., Fuentes-Farias, A. L., and Melendez-Herrera, E. (2016). ACAID as. Med. Hypotheses 88, 38-45.

Uc, E. Y., Rizzo, M., Anderson, S. W., Qian, S., Rodnitzky, R. L., and Dawson, J. D. (2005). Visual dysfunction in Parkinson disease without dementia. Neurology 65, 1907-1913. doi: 10.1212/01.wnl.0000191565.11065.11

Uchida, A., Pillai, J. A., Bermel, R., Bonner-Jackson, A., Rae-Grant, A., Fernandez, H., et al. (2018). Outer retinal assessment using spectral-domain optical coherence tomography in patients with Alzheimer's and Parkinson's disease. Invest. Ophthalmol. Vis. Sci. 59, 2768-2777. doi: 10.1167/iovs.1723240

van der Holst, H. M., van Uden, I. W. M., Tuladhar, A. M., de Laat, K. F., van Norden, A. G. W., Norris, D. G., et al. (2015). Cerebral small vessel disease and incident parkinsonism. The RUN DMC study. Neurology 85, 15691577.

Vecino, E., Rodriguez, F. D., Ruzafa, N., Pereiro, X., and Sharma, S. C. (2016). Glianeuron interactions in the mammalian retina. Prog. Retin. Eye Res. 51, 1-40. doi: $10.1016 /$ j.preteyeres.2015.06.003

Videnovic, A., Klerman, E. B., Wang, W., Marconi, A., Kuhta, T., and Zee, P. C. (2017). Timed light therapy for sleep and daytime sleepiness associated with parkinson disease: a randomized clinical trial. JAMA Neurol. 74, 411-418. doi: 10.1001/jamaneurol.2016.5192

Visser, F., Apostolov, V. I., Vlaar, A. M. M., Twisk, J. W. R., Weinstein, H. C., and Berendse, H. W. (2020). Visual hallucinations in Parkinson's disease are 
associated with thinning of the inner retina. Sci Rep 10:21110. doi: 10.1038/ s41598-020-77833-1

Weil, R. S., Schrag, A. E., Warren, J. D., Crutch, S. J., Lees, A. J., and Morris, H. R. (2016). Visual dysfunction in Parkinson's disease. Brain 139, 2827-2843.

Williams, D. R., Warren, J. D., and Lees, A. J. (2008). Using the presence of visual hallucinations to differentiate Parkinson's disease from atypical parkinsonism. J. Neurol. Neurosurg. Psychiatry 79, 652-655. doi: 10.1136/jnnp.2007.124677

Willis, G. L. (2005). The therapeutic effects of dopamine replacement therapy and its psychiatric side effects are mediated by pineal function. Behav. Brain Res. 160, 148-160. doi: 10.1016/j.bbr.2004.11.030

Willis, G. L. (2008). Intraocular microinjections repair experimental Parkinson's disease. Brain Res. 1217, 119-131. doi: 10.1016/j.brainres.2008.03.083

Willis, G. L., and Freelance, C. B. (2017). Neurochemical systems of the retina involved in the control of movement. Front. Neurol. 8:324. doi: 10.3389/fneur. 2017.00324

Willis, G. L., Moore, C., and Armstrong, S. M. (2014). Parkinson's disease, lights and melanocytes: looking beyond the retina. Sci Rep 4:3921. doi: 10.1038/ srep03921

Wojtkowski, M., Bajraszewski, T., Gorczynska, I., Targowski, P., Kowalczyk, A., Wasilewski, W., et al. (2004). Ophthalmic imaging by spectral optical coherence tomography. Am. J. Ophthalmol. 138, 412-419.

Wong, C., Ishibashi, T., Tucker, G., and Hamasaki, D. (1985). Responses of the pigmented rabbit retina to NMPTP, a chemical inducer of parkinsonism. Exp. Eye Res. 40, 509-519. doi: 10.1016/0014-4835(85)90073-9

Wong, T. Y., Klein, R., Couper, D. J., Cooper, L. S., Shahar, E., Hubbard, L. D., et al. (2001). Retinal microvascular abnormalities and incident stroke: the atherosclerosis risk in communities study. Lancet 358, 1134-1140. doi: 10.1016/ S0140-6736(01)06253-5

Xu, L., Lee, J. R., Hao, S., Ling, X. B., Brooks, J. D., Wang, S. X., et al. (2019). Improved detection of prostate cancer using a magneto-nanosensor assay for serum circulating autoantibodies. PLoS One 14:e221051. doi: 10.1371/journal. pone. 0221051
Yavas, G., Yilmaz, O., Küsbeci, T., and Oztürk, F. (2007). The effect of levodopa and dopamine agonists on optic nerve head in Parkinson disease. Eur. J. Ophthalmol. 17, 812-816. doi: 10.1177/112067210701700520

Yenice, O., Onal, S., Midi, I., Ozcan, E., Temel, A., and Gunal, I. D. (2008). Visual field analysis in patients with Parkinson's disease. Parkinsonism Relat. Disord. 14, 193-198. doi: 10.1016/j.parkreldis.2007.07.018

Zhang, J., Richmond, A. M., and Ogilvie, J. M. (2014). Inhibition of dopamine signaling suppresses cGMP accumulation in rdl retinal organ cultures. Neuroreport 25, 601-606. doi: 10.1097/WNR.0000000000000145

Zhang, Y., Weng, H., Li, Q., and Wang, Z. (2018). Changes in retina and choroid after haemodialysis assessed using optical coherence tomography angiography. Clin. Exp. Optom. 101, 674-679. doi: 10.1111/cxo.12660

Zhu, K., van Hilten, J., Putter, H., and Marinus, J. (2013). Risk factors for hallucinations in Parkinson's disease: results from a large prospective cohort study. Mov. Disord. 28, 755-762. doi: 10.1002/mds.25389

Conflict of Interest: The authors declare that the research was conducted in the absence of any commercial or financial relationships that could be construed as a potential conflict of interest.

Publisher's Note: All claims expressed in this article are solely those of the authors and do not necessarily represent those of their affiliated organizations, or those of the publisher, the editors and the reviewers. Any product that may be evaluated in this article, or claim that may be made by its manufacturer, is not guaranteed or endorsed by the publisher.

Copyright (c) 2022 Zhang, Zhang, Yue and Tian. This is an open-access article distributed under the terms of the Creative Commons Attribution License (CC BY). The use, distribution or reproduction in other forums is permitted, provided the original author(s) and the copyright owner(s) are credited and that the original publication in this journal is cited, in accordance with accepted academic practice. No use, distribution or reproduction is permitted which does not comply with these terms. 